\title{
Measuring the effect of spell recurrence on poverty dynamics: Evidence from Spain ${ }^{*}$
}

\author{
José María Arranz* \\ (Universidad de Alcalá) \\ Olga Cantó \\ (Universidade de Vigo)
}

\begin{abstract}
The analysis of poverty dynamics yields important insights about the nature of poverty and the expected effectiveness of alternative social policies in order to fight against it. The recent literature on poverty dynamics proposes various approaches to the measurement of the effects of poverty spell length and the experience of multiple-spells on poverty exit or re-entry rates. However, none of the proposals in the literature considers the expected effect on transition probabilities of the accumulation of poverty spells in an individual's poverty history. This paper proposes the estimation of a hazard regression model where the individual probability of leaving and entering poverty is affected by the length of the current poverty spell, the fact that the individual experiences repeated spells which accumulate in time. Results indicate that poverty transitions still show some negative duration dependence even if we introduce controls for unobserved heterogeneity and lagged durations. The duration of previous poverty spells reduces the exit and increases the re-entry hazard. Finally, estimating separate hazards by spell order allows for some control for the relevant impact of left-truncation on results and shows the significant differences in the covariates that turn out to promote transitions for individuals that often fluctuate into and out of poverty (transitory poor) in comparison with those that suffer a rather more persistent poverty experience (chronic poor).
\end{abstract}

Keywords: poverty dynamics, discrete-time hazard regression models, multiple spells.

JEL Classification: D1, D31, I32.

\footnotetext{
* Authors are grateful for the finance support obtained from the Instituto de Estudios Fiscales (IEF) in order to undertake this research project. Olga Cantó is also grateful for the finance from the Ministerio de Educación y Ciencia (SEJ2004-07373-C03-02) and the Xunta de Galicia (PGIDIT05PXIC30001PN). Special thanks go also to Maite Blázquez for helpful discussions on the matter and to all participants in a Seminar in Alicante (Spain) in May 2007 for their comments and suggestions. The paper was presented at the ECINEQ Conference in Berlin and at the VII Jornadas de Economía Laboral in Las Palmas de Gran Canaria in july 2007. The usual disclaimer applies.

* Departamento de Estadística, Estructura Económica y OEI, Universidad de Alcalá. Plaza de la Victoria 2, Alcalá de Henares 28802, Madrid, Spain. e-mail: josem.arranz@uah.es

- Departamento de Economía Aplicada, Facultade de CC. Económicas e Empresariais, Universidade de Vigo, Campus de Lagoas Marcosende s/n, 36310 Vigo (Pontevedra), Spain, Tel: +34 986813530 or 802028, Fax: +34 986812401, e-mail: ocanto@uvigo.es
} 


\section{Introduction}

The literature centred on the analysis of the lowest part of the income distribution has produced a large amount of work on the dynamics of poverty in recent years. A first interesting result of this research is the proposal of a new dimension in the measurement of poverty which refers to the time individuals spend below the poverty line. Certainly, in the analysis of poverty it is of great interest to be able to characterise the complete low income pattern of individuals along time.

The advantage of distinguishing the characteristics of individuals that suffer from persistent poverty in contrast with those that experience poverty for a relatively short time, is that different policies may be designed in fighting against each of these situations. Fighting against long-term or persistent poverty will imply designing educational and health policies for poor children and offering stable complementary monetary transfers for poor adults. In contrast, transitory poverty could benefit from short-term labour market policies promoting employment stability and some shortperiod money transfers working as income substitutes. For this second group, we believe that it certainly becomes important to investigate the relevance of poverty spell recurrence and, most importantly, to measure to what extent the probability of leaving a poverty spell depends on having had a previous experience in poverty with a varied length. The relevance of distinguishing recurrence within the transitory poor becomes particularly evident after one of the key findings of the OECD (2001) report: “...the typical year spent in poverty is lived by persons who experience multiple years of poverty and whose long-term incomes are below the poverty threshold on average, even though their yearly income may periodically exceed the poverty threshold” (Chapter 2, $1^{\text {st }}$ page).

The literature on poverty dynamics has largely focussed on the analysis of spells and the estimation of entry and re-entry hazards after the seminal works of Allison (1982) and Bane and Ellwood (1986) which have recently been fostered by Stevens (1999), Devicienti (2001) or Biewen (2006). These papers study the extent and composition of chronic poverty in a variety of countries using a hazard rate approach that accounts for multiple spells of poverty and incorporates spell duration, individual 
and household characteristics and unobserved heterogeneity. In general, previous hazard rate approaches assume that the consideration of individual unobserved heterogeneity captures the correlation across individual spells and thus identifies four types of individuals in the sample through a joint distribution of individual specific effects with respect to spells of poverty and non-poverty. This assumption imposes the estimation of a single exit and re-entry hazard rate for each individual independent of the number of poverty spells previously experienced. In contrast, our approach stems from believing that the complete individual poverty history may play a relevant role, in itself, in determining the likelihood of experiencing a new poverty or non-poverty spell. Therefore, predicted exit and re-entry hazards should incorporate the information on both the duration and the accumulation of spells. In fact, it could be the case that the relative importance of unobserved characteristics in determining poverty exit and reentry hazard rates may, in part, hide a genuine spell accumulation effect that can be distinguished if we allow poverty exit and re-entry hazards to vary as spells accumulate.

Even if this particular issue is virtually unexplored in the literature on the dynamics of poverty and social exclusion, in the literature on labour economics there is already an important number of papers devoted to the analysis of recurrent unemployment and its effects on the individual's probability of leaving unemployment in a forthcoming spell i.e. the relevance of unemployment history on a current unemployment spell. These models were introduced by Lancaster (1990) and are popular in the labour economics literature because they can easily incorporate variables that change over time and censored spells while they also allow one to examine how the probability of leaving poverty changes with spell duration and when spells accumulate. Examples of this literature in the analysis of unemployment spells can be found in Heckman and Borjas (1980), Trivedi and Alexander (1989), Bonnal et al. (1997), Omori (1997) or Arranz and Muro (2004, 2007). Some of these papers state that the duration of previous spells can contain valuable information about individual types, with the result being that the durations of previous spells would significantly reduce the exit hazard.

Following these approaches we tackle the complete analysis of the influence of poverty history on exit and re-entry hazards in Spain by estimating hazard rates that consider all the information available on the individual poverty situation using the 
European Community Household Panel dataset (hereinafter, ECHP) for the period 1994-2000. The case of Spain is of particular interest for the measurement of poverty recurrence within the European context given that there is a relatively large percentage of individuals who suffer from transitory poverty (see OECD, 2001) in comparison with other countries. In particular, if one focuses on the working-age population, Spain stands out as the European country with one of the highest levels of short-term poverty (poor at least once in three years) with figures that are even slightly over those observed in the US and Canada.

Regarding the debate in the literature on the adequacy of including left-censored spells or not in the analysis of poverty patterns in time, the issue is not yet clearly solved. The dilemma is that, on the one hand, there is a sample selection bias noted by Stevens (1997) and Iceland (1997) if they are eliminated but, on the other hand, if they are included we would also generate a bias in results on spell duration if they are treated in the same way as non-left-censored spells. This paper proposes a methodology that is able to include them in the analysis in an advantageous way.

Thus, our paper contributes to the literature on poverty dynamics in several ways: First, we aim to contribute to the debate on the determinants of the probability of leaving poverty by trying to disaggregate the distinct effects of unobserved heterogeneity and duration dependence. Secondly, our approach allows for different poverty exit, entry and re-entry hazards when spells accumulate, challenging previous studies based on poverty persistence that estimate one exit and one re-entry hazard rate independent of the number and duration of individual poverty experiences. Thirdly, since omitting the left-truncated spells would lead to serious selection bias (see Iceland 1997) our methodology is able to incorporate them in the analysis by distinguishing them from higher order spells. Our strategy allows us discuss the substantive differences in results when analysing exit hazard rates for first-spells for individuals in poverty at first interview (for whom the poverty spell is in progress) and new entrants to poverty within our largest possible window of analysis. Finally, the use of time-varying covariates within each spell in the estimation of the exit and re-entry hazards, allows us to aim for the best possible fit of the individual's complete poverty experience. 
The paper is organized as follows. Section 1 presents the most important previous results in the literature on the analysis of poverty dynamics in general and poverty outflow in particular. In Section 2, we describe the longitudinal data set used, detailing the definition of the variables and undertaking a thorough descriptive analysis of the observed poverty and non-poverty spells in the Spanish dataset. Section 4 presents the econometric model while Section 5 discusses the main estimation results. Finally, Section 6 concludes by presenting our main findings.

\section{Some previous approaches in the literature}

The analysis of the dynamics of poverty was initiated in the United States during the eighties, mainly as a result of the availability of a mature and reliable longitudinal data survey: the Panel Survey of Income Dynamics (PSID), ongoing since $1968 .{ }^{1}$ In the European context it is only in the beginning of the nineties that Duncan et al. (1993) try to compare, for the first time, the duration of poverty in a group of countries using a variety of data sources. ${ }^{2}$ Fortunately for the development of this literature, in 1994 the European Statistical Office decided to obtain accurate and comparable longitudinal data information for most countries in the European Union initiating the ECHP Survey which, after some years, has become a basic tool for the analysis of social cohesion dynamics in the European Union. The exploitation of this dataset, together with the information from some nationally based panels available for some particular countries such as the British Household Panel Survey (BHPS) for the U.K., the German Socioeconomic Panel (GSOEP) for Germany or the Encuesta Continua de Presupuestos Familiares (ECPF)

\footnotetext{
${ }^{1}$ One of the most relevant papers in this literature published in that period are Allison (1982) and Bane and Ellwood (1986). Other interesting papers are Hill (1981), Plotnick (1983), Duncan (1984) or Sawhill (1988).

${ }^{2}$ This is first the paper on poverty dynamics in Europe that we know of, authors compare the duration of poverty in Germany, Sweden, The Netherlands and Luxembourg and in the Lorena region (France).
} 
for Spain, has allowed a large list of researchers to present plausible answers to important issues related to the duration and persistence of poverty in Europe. ${ }^{3}$

The development of new statistical techniques in the estimation of transition probabilities that take state dependence into account, as Aassve et al. (2005) note in their literature revision, has produced an important number of ways to estimate transition risks. In the first place some papers have used components of variance models to capture the dynamics of income using a complex error structure. ${ }^{4}$ These models are able to predict the fraction of the population likely to be in poverty for different lengths of time. This methodology has the advantage of including all individual income information in time and avoiding the ex-ante definition of poverty using a binary indicator. Its main disadvantage, however, is that it assumes that the dynamics of the income process is identical for all individuals in the sample, whatever their income level. Clearly, this does not seem to match reality and, in fact, Stevens (1999) and Devicienti (2001) conclude that, in comparison with duration models, components of variance models perform worse in fitting observed patterns of poverty in the US and the UK respectively. ${ }^{5}$

Some other recent approximations to the estimation of outflow hazard rates propose the estimation of Markovian transition models (first order Markov) taking simultaneously into account that individuals are not randomly distributed either within the poor at first interview (initial conditions problem) or within the effectively observed at second interview (attrition problem) - see Cappellari and Jenkins (2002 and 2004). In some sense, this type of approach focuses on sample heterogeneity and avoids assigning relevance to spell duration or persistence in the determination of the outflow rate, which is in line with the arguments raised by Blumen et al. (1955) in order to explain why empirical transition matrices underestimate the main diagonal of the matrix thus biasing downwards any estimation of persistence.

\footnotetext{
${ }^{3}$ Examples of these are Jarvis and Jenkins (1996), Cantó (1998), Antolín et al. (1999), Jenkins and Rigg (2001), Devicienti (2001), Gradín et al. (2004), Aassve et al. (2005), Biewen (2006) or Cantó et al. (2007).

${ }^{4}$ Examples of this approach are Lillard and Willis (1978), Stevens (1999) and Devicienti (2001).

${ }^{5}$ However, this result does not necessarily imply that these models perform worse in the estimation of the effects of explanatory variables on transition risk.
} 
Some more recent approaches to the analysis of poverty transitions choose to use binary dependent variable dynamic random effects models where the poverty situation at moment $t$ depends on the fact that you were poor at $t-1$, a list of covariates and some unobserved individual effect. In this case state dependence is summarized by the coefficient estimated for lagged poverty. In this way Wooldridge (2005) models the distribution of the unobserved effect conditional on the initial value of poverty (initial conditions) and a group of exogenous variables. ${ }^{6}$

A different view on the matter was offered by Shorrocks (1976) who attributed the phenomenon to a violation of the first-order Markov assumption which implies that the extension of the Markov process, in as much as the longitudinal information allows us to is the way to proceed in the accurate estimation of the outflow rate. In this second line of argument, a long-standing approach to model poverty transitions has been the use of discrete duration models in a hazard rate framework. Since the relevant contributions to this literature due to Kalbfleisch and Prentice (1980), Allison (1982), Duncan (1984) or Bane and Ellwood (1986), a large list of papers have developed single-spell duration models based on Markov chains that allow for the estimation of the transition probability taking into account all the relevant longitudinal information offered by panel datasets. A relevant contribution to the easy estimation of hazard rates as an n-Markov chain by using a simple logit or probit model was proposed by Jenkins (1995). ${ }^{7}$

\footnotetext{
${ }^{6}$ Examples of this approach to the analysis of the dynamics of poverty appear in Biewen (2004), Hansen et al. (2006) and Poggi (2007).

${ }^{7}$ Empirical applications of this methodology selecting a poverty inflow sample of spells for Spanish data referred to the 1985-1995 period appear in Cantó (2002, 2003). Finnie and Sweetman (2003) use this methodology on administrative data to estimate exit and re-entry transitions for Canadian individuals not including unobserved heterogeneity but stratifying the sample by family status (single, couple with/without children and lone parents) and including events as a relevant reason for transitions occurrence. Cantó et al. (2007) use a similar strategy to estimate exit transitions for Spanish households distinguishing between households with and without children and including a large list of events as explanatory variables of the transition equation. A single-spell approach is also used by Fouarge and Layte (2005) who estimate the exit probability using a single-spell approach but including unobserved heterogeneity an individual specific error term with Gaussian distribution and assume a Weibull hazard rate model for the exit probability. Much more simple is the methodology in Valletta (2006) who uses a pool of transitions to estimate the probability of leaving and entering poverty for a sample of individuals living in working-age households including labour market and demographic events as explanatory variables but without considering the effect of duration, unobserved heterogeneity or past poverty occurrences.
} 
However, a list of recent papers have highlighted the limitations of the use of single spells approaches in the fitting the observed pattern of poverty persistence and have proposed a new methodology that allows for the consideration of multiple poverty and non-poverty spells simultaneously. This methodology was first proposed by Stevens (1999) and then used by Devicienti (2001), Hansen and Wahlberg (2004) and Biewen (2006). ${ }^{8}$ These papers do not only consider the estimation of the probability of leaving a poverty spell but are able to estimate the hazard rate for multiple spells while controlling for unobserved heterogeneity, an important source of bias for the estimated coefficients for duration. ${ }^{9}$ However, this methodology has an important disadvantage for studying recurrence given that it only allows for the estimation of a single exit and re-entry hazard rate independent of the number of poverty experiences that the individual may have accumulated in time. This means that, virtually, the recurrence of poverty spells is assumed not to affect the estimated probability of transition.

The analysis presented here borrows from a tested methodology in the labour economics literature on the analysis of unemployment spells that allows us, in a very simple way, to improve our knowledge on to what extent the accumulation of poverty

${ }^{8}$ Devicienti (2001) adds the consideration of the initial conditions problem by adjusting the contribution to the exit hazard rate of those individuals who are already below the poverty line at first household interview. In general, in most available datasets the lack of information on the previous household socioeconomic situation implies that most papers must either avoid to use left-censored observations or avoid the inclusion of duration as a explanatory variable. However, Devicienti (2001) reports that fitting his type of model is computationally too demanding for a relatively short panel dataset of eight years like the ECHP. Hansen and Wahlberg (2004) use this same approach for data from Swedish administrative records which imply no attrition and a most accurate income measurement. Biewen (2006) shows how correct standard errors (not affected by the correlation between individuals from the same household) can be computed for the hazard rate model by taking into account clustering of observations at the household level. These standard errors are relevant in order to construct confidence intervals to compare the hazard rate with the components-of-variance approach. Other recent papers as Fertig and Tamm (2007) have followed a similar methodology to that of Devicienti (2001) including Biewen's correct standard errors. These authors analyse the duration of child poverty in Germany trying to contribute to the literature by reducing the effect of left-censored spells on results. In order to do so they select a sample of newly born children. However, the problem these authors face is that left-censoring in poverty is a household matter and not an individual specific problem so their strategy, in our point of view, is hardly able to improve our research knowledge of how results would change if we could use a proper non-left-censored spells sample.

${ }^{9}$ These approaches recognise explicitly the existence of two processes that can generate persistence: unobserved heterogeneity and true state dependence. In the first process, individuals could be heterogeneous with respect to characteristics that reduce their probability of leaving poverty (think for example that some unobserved persistent individual characteristic reduces the probability that the individual experiences a positive event between t-1 and t, i.e. being lazy, being an alcoholic or drug consumer, etc.). In the second process, experiencing poverty in a specific time period, in itself, increases the probability of undergoing poverty in subsequent periods. 
spells and the individual poverty history (lagged poverty and non-poverty durations) has a relevant role in determining future poverty risks within a discrete duration model framework. Therefore, we aim to relax the assumption on the independence of the recurrent poverty experiences while controlling for unobserved heterogeneity and allowing for the inclusion of time-varying covariates. ${ }^{10}$

We examine the persistence of poverty during a seven year period using data for Spain from 1994 to 2000 and jointly estimating various hazard rates, one for leaving poverty and another one for entering or re-entering poverty by spell order and including lagged spell durations as explanatory variables. We believe that our methodology is analogous to what is usually called a multi-state multiple transition discrete hazard regression model with unobserved heterogeneity as in Callens et al. (2005), where the relevance of spell accumulation is explicitly considered so we can check if the effect of covariates is different when poverty experiences are recurrent. This strategy also allows us to easily integrate some control for left-truncation by separating left-censored poverty spells from the rest, labelling them as first spells in our life-table and hazard regressions analysis ${ }^{11}$, subsequently we replicate all relevant calculations for a sample of new-entrants to poverty that restricts the analysis to individuals who are observed to become poor within the observation window, most precisely at their second interview in the panel (in 1995). ${ }^{12}$

\section{The ECHP data set.}

\footnotetext{
${ }^{10}$ An alternative methodology that tries to account for the way in which past poverty can have an effect on future poverty and thus aims to relax the assumption on the independence of the recurrent poverty experiences has been developed by Biewen (2004). This paper is related to the attempts to model poverty transitions in a more structural way initially proposed by Burgess and Propper (1998) and recently simplified by Aassve et al. (2005). These approaches propose a comprehensive model of poverty dynamics by modelling demographic and employment processes that underlie the poverty outcome. The main problem these models face is the need to simplify the large number of simultaneous risks for each household member given the limited number of equations and parameters one can identify. Further, a series of assumptions are to be made in terms of the fertility and employment process and this becomes most difficult in socioeconomic contexts where these processes and their income effects are largely unexplored.

${ }^{11}$ Note that this implies a form of control for left-truncation.

${ }^{12}$ These two strategies are referred to as convenient in Iceland (1997). The author refers to the fact that, even if they do not solve the problem of left-truncation they shed light on the issues of interest. The second strategy was used by Moffitt and Rendall (1993) in their study on lifetime distribution of female headship in the U.S.
} 


\subsection{A short description of the ECHP data set.}

The dataset we use is constructed using the information for Spain from the European Community Household Panel (hereinafter, ECHP) for the period 1994-2000. The dataset used was designed by Eurostat in order to obtain country-comparable statistics on many demographic and socio-economic aspects of the European population related to labour market issues, income, living standards, education, employment and not employment-related satisfaction, health and migration, among others. The ECHP collects information about individual age, sex, education, income and labour market status together with an important amount of family composition variables.

The ECHP is annually based and has a longitudinal structure that allows following individuals during eight years, unless they voluntarily leave the survey earlier. ${ }^{13}$ Most of the variables included in the survey describe the individual's and household's situation at the moment of the interview (1994 along to 2001) or refer to information on the current month. However, the information on annual individual income from a variety of sources refers to that obtained by the individual during the year previous to the interview. Thus, in the construction of the relevant income variable to determine the individual situation of poverty in a given year we believe that it is important to make demographic and income information contemporaneous, especially if we wish to include time-varying covariates or events as explanatory variables of poverty flows. This means that we have to drop the information on incomes for 1993 (declared in 1994) and on characteristics for 2001 which implies that we finally use the information from seven complete waves instead of eight. ${ }^{14}$ The advantage of this procedure is that the definition of poor is based on contemporaneous information on incomes and needs which becomes crucial when we aim to correctly measure the effect of demographic or socioeconomic events on the individual's probability of experiencing a transition.

\footnotetext{
13 This would imply the existence of attrition which is taken into account in the survey by the use of longitudinal weights.

${ }^{14}$ It is important to note here that given that individuals change households by creating a new one between two consecutive interviews (emancipation, divorce or separation), we must make some adjustments to household income so that individuals that change household effectively contribute to the income of the household where they were when household characteristics were observed. Clearly, if attrition occurs this strategy implies that we lose information on some individuals and our sample reduces. In fact, our final sample reduces between a 9 to 14 percent with respect to a noncontemporaneous sample depending on the year considered - see Table A2.
} 


\subsection{Sample selection and descriptive analysis}

The period of observation in our study is from 1994 to 2000 and our sample includes individuals with a complete interview in the survey ${ }^{15}$ and whose household reports previous year income information. ${ }^{16}$ As noted earlier, our sample reduces slightly, see Table A2, when we match demographic and socioeconomic characteristics with yearly income so that we have contemporaneous information on both. Thus, our sample for 1994 includes 19,044 individuals of which 15,042 (79 percent) are adults and 4,002 (21 percent) are children below 16 years of age.

For the purposes of our investigation, we use the standard definition of poverty, thus an individual is poor if total household income of the household he or she lives in is less than 60 per cent of the contemporary household median income. The results on static poverty for this sample are reported in Figure 1 that shows how individual adult poverty rates were quite stable during the period under study.

\section{[place Figure 1 around here]}

Regarding the particular characteristics of poverty dynamics in Spain, and limiting our sample to those individuals that are observed at all interviews, Table 1 provides a variety of measures on chronic, transitory and recurrent poverty in order to contrast our results with those of other works on the matter such as Valletta (2006) or OECD (2001). In particular, the OECD (2001) chapter on poverty dynamics calculates that the always poor in Spain were 8.3 per cent of the sample in the first three years of the ECHP, one of the highest percentages in the European Union context. Only Greece, Italy and Portugal register a larger percentage while Denmark registers the lowest percentage with a 2.6 percent. In particular, the characteristics of poverty duration in Spain are reported there to be significantly different for individuals living within working-age households compared to the rest. Our results using the complete ECHP data confirm this result.

\footnotetext{
15 We eliminate between a 1 and 2 percent of individuals due to the lack of complete interview - see Table A1.

${ }^{16}$ We lose less than 1 percent of individuals most of the years due to the lack of information on previous year household income.
} 
First, Table 1 shows that the mean annual poverty rate in Spain is significantly higher for households whose head is below 64 years of age than otherwise. In terms of dynamics, results in this table show that working-age households in Spain suffer a similar level of chronic poverty compared to the rest but a significantly higher level of transitory poverty ${ }^{17}$. In particular, while having one poverty spell takes place with a similar probability in both population groups, having two, three or more spells happens much more often to those individuals in working-age households than to the rest. Thus, recurrent poverty in Spain seems to be linked to working-age households whose main members are active in the labour market.

Table 1 also shows that leaving left-censored spells out of the analysis of dynamic poverty in Spain is most likely to be biased against working-age households with recurrent poverty spells because a larger percentage of recurrent spells are experienced by this household type. Thus, a strategy that considers these spells, distinguishing them from the rest, seems particularly adequate in this case.

\section{[place Table 1 around here]}

However, in order to construct our final sample to be in our final sample for dynamics analysis, we select individuals present in the 1994 sample and in all consecutive interviews until either the survey ends or they suffer from attrition (they leave prior to the end of the survey). ${ }^{18}$ Thus individuals joining the survey after 1994 are not included in our sample. After this selection we have an unbalanced panel of individuals that we will use for a preliminary descriptive analysis of poverty incidence, poverty persistence and poverty transition rates using conditional probabilities

\footnotetext{
${ }^{17}$ Note that this result is different depending on the indicator used. Those indicators which are not affected by transitory poverty, such as the "percentage of always poor", show a similar level of chronic poverty in both groups. If one uses the "percentage of poor 5 waves out of 7" or the "poor at least once" indicators, which are contaminated by transitory poverty, one finds a higher level of poverty in workingage households due to the contribution of short-term or transitory poverty. A similar effect is captured by the "permanent-income poor" indicator which sums all households incomes along the period and calculates the percentage of households whose total income in the seven-year period is below the $60 \%$ median income of the total sample during the whole period.

${ }^{18}$ Note that if the individual leaves prior to the end of the survey the ongoing spell will be treated as rightcensored.
} 
calculations - see Table 2. ${ }^{19}$ Results from Table 2 indicate that, as in the cross-sectional sample, the pattern of static poverty in our sample for analysis is quite flat: the incidence of poverty is pretty stable between 19-21 per cent of the households in the sample.

Some preliminary results on transitions are also reported in Table 2, these are obtained by calculating the conditional probability that the individual is in a certain situation at moment $t$ given his/her situation in the previous year, $t-1$. The first row of these conditional probabilities indicates the individual probability of remaining in poverty in two consecutive interviews i.e. two-year poverty persistence. Some 52 per cent of individuals who were poor in 1994 continue to be in poverty in 1995. In subsequent waves, this conditional probability fluctuates only slightly from 49 per cent in 1996 to just 55 per cent in 2000. Thus, for the entire period, these results show that there is a considerable persistence in poverty, a mean of almost 53 per cent of individuals who where poor at time $t-1$ are also poor one year later. As expected, transition probabilities from poor to non-poor are higher than from non-poor to poor but entry and exit from poverty do not seem to have a clear pattern along the period. ${ }^{20}$ Interestingly, the probability of attrition does not appear to be determined by the individual poverty situation. Indeed, even if in 1995 and 1997 the probability of attrition was slightly higher for the group of the poor (approx. 12.5 versus 10.5 per cent), this difference is not observable at any other moment.

[place Table 2 around here]

Our econometric estimations of transitions rates will require individual consecutive observations (to allow for current and lagged poverty and re-entry spells) and a common date of entry to the panel - see Heckman (1981). Therefore, our sample of individuals for analysis is an unbalanced panel of 3,664 individuals who were poor in

\footnotetext{
${ }^{19}$ This first unbalanced sample includes 19,044 individuals (a total of 99,507 person-year observations) and, as it would be expected due to attrition, the sample size falls along the period. Table A3 in the appendix contains a similar analysis for the total sample from the panel without any selection. As one can easily check it appears that results are remarkably similar.

${ }^{20}$ Our results in this table match those obtained for the period 1994-1996 by the OECD (2001) report where using an OECD equivalent scale and a $60 \%$ of the median income poverty line the headcount index is 19.2 , the entry rate is 8.3 and the exit rate is 39.7 .
} 
1994 and have consecutive observations in the panel. ${ }^{21}$ Given that the incidence, shortterm persistence and recurrence remained quite constant across the period we believe that this sample selection is particularly adequate in this context. This choice allows us to use the longest observation window possible and provides us with a stock of 3,664 individuals in poverty whose first poverty spell is, by definition, in progress at the start of the sample period. ${ }^{22}$ This sample's first spells are all left-censored poverty spells for which duration is unknown because the start date is missing. By definition, second, third or fourth spells are non-left-censored. However, some of the poverty and nonpoverty spells will be right-censored because they will be still in progress at the end of the ECHP time window. For the latter we only know that the elapsed time of the spell was longer than the interval between the spell start date and the end of the ECHP observation window (1994-2000): censored durations. Clearly, ending spell dates are only known for those spells that are observed to finish within the observation window. ${ }^{23}$

With the analysis of this sample we are ignoring the fact that we are not able to determine the real duration of left-censored spells. ${ }^{24}$ Note, in any case, that erasing leftcensored spells in progress at the start of the sample (even if considering unobserved heterogeneity) provokes a form of sample selection bias as Stevens (1997) and Iceland (1997) indicate. ${ }^{25}$ Indeed, if we select only those individuals who are observed to enter poverty in 1995 and follow their future movements into and out of poverty across the period 1994-2000 - see Table A4 in the Appendix -, the conditional transitions from non-poor to poor obtained from this sample, are significantly higher than those reported

\footnotetext{
${ }^{21}$ This means that we require an individual not to have missing observations in between interviews to be included in this dataset. This sample amounts to a total of 19,219 person-year observations.

${ }^{22}$ Note here that we cannot distinguish if the spell began precisely in 1994 or was in progress before the start of the sampling period. This sample doest not include individuals who started the ECHP and may temporarily exit the ECHP presenting missing values across several years (because we do not know their status of poverty and non-poverty). There are 333 individuals of this type who experience 1,496 poverty spells.

${ }^{23}$ Note here that the duration of the spells (of poverty or non-poverty) of those individuals who leave prior to the end of the survey (attrition) are also considered as right censored observations. It would be of interest to analyse the effect on duration of deleting right censored observations.

${ }^{24}$ Note that this is also the choice in the descriptive analysis undertaken by Stevens (1999) or Jenkins and Rigg (2001).

${ }^{25}$ It is easy to see that if we were to eliminate them, and only consider individuals who begin a new spell after 1994, thus in 1995 for the first time, we would overstate transition probabilities given that the selected sample would have experienced at least one transition (non-poor to poor) since 1994.
} 
for the complete sample in Table 2 or even the first sample in Table A3 (they range from 14 percent to 32 percent while those for the first sample are almost always below a 10 percent). ${ }^{26}$ However, we will return to this issue later in order to analyse, in detail, the consequences of keeping left-censored spells in the sample on our results. ${ }^{27}$

Results on poverty incidence and persistence using our selected sample are reported in Table $3 .^{28}$ We observe that, in comparison with our first sample, the individual's probability of stepping into of poverty is now significantly higher (more than a double the risk of transition than our first sample in Table 2: 7.8 to 8.5 compared to 24.2 to 19.2$).{ }^{29}$ In contrast, individuals in this second sample show a higher persistence in poverty (53 to 65 percent depending on the year compared to 49.4 to 55 percent) and thus also a lower probability leaving poverty at any two subsequent interviews. Also they show a lower persistence out of poverty which implies that they are more likely to suffer poverty recall. In sum, this sample includes more chronic poor but also more short-term recurrently poor individuals than our first sample.

\section{[place Table 3 around here]}

Results on spell duration pooling the data for all the poverty and non-poverty periods without considering the order of each occurrence are reported in Table 4 . The last row of this Table reflects the long-term persistence of poverty in Spain in the period under analysis: 9.4 per cent of individuals who are poor in 1994 continue to be below the poverty line seven years later, ${ }^{30}$ this percentage rises to 12 per cent for those who are

\footnotetext{
${ }^{26}$ However, note that the estimations of models ignoring unobserved heterogeneity or omitted variables which only include spells that begin after the start of the sample, give consistent estimates of poverty transition rates for the population, Heckman and Singer (1984).

${ }^{27}$ It is not possible for us to model the hazard rate of an individual's first entry into poverty or first exit from poverty (initial conditions) because we do not have information on the pre-1994 income histories of those who were poor (or not) before 1994. Our only control for left-censoring is to estimate a separate baseline hazard for left-truncated spells as Callens et al. (2005) suggest. An extension to our work could consider the suggestions of Arulampalam and Stevens (page 562) in order to tackle the influence of leftcensoring on results.

${ }^{28}$ In the appendix we include a similar table for three types of individuals: those aged below 16 years, those between 16 and 65 and those aged above 65 (See Table A6.-A8.).

${ }^{29}$ This appears a reasonable effect of selecting individuals already touched by poverty in 1994 .

${ }^{30}$ Note that this percentage drops to approximately a 3 per cent of individuals if we consider a balanced sample of those interviewed in all seven waves but we do not condition on being poor at first interview in 1994, as reflected in our previous Table 1.
} 
able to step out of poverty for a year but come back to it suffering a second poverty spell of, at least, 6 years of length. We find that nearly 30 per cent of the individuals remain four years or more in poverty and 35.5 per cent of the individuals who exit poverty (thus enter a non-poverty period) remain one year in non-poverty, 22.5 per cent two years and 12 per cent at least six.

\section{[place Table 4 around here]}

Tables 5 and 6 focus on the frequency distribution of elapsed poverty and nonpoverty spells by order of occurrence of the particular spell. Our findings in these tables highlight the importance of considering multiple spells in the analysis of poverty dynamics: out of the 3,664 individuals who are in poverty since 1994, 27 percent have two occurrences along the time of observation and nearly 7.5 per cent have three or more occurrences. This implies that a 35 percent of the individuals re-enter poverty during the seven year period and more than 7 percent re-enter twice or three times. In terms of duration, first-spells have a mean duration of two and a half years while the duration of second and third poverty spells is slightly shorter (1.7 and 1.3 years respectively). ${ }^{31}$

Indeed, Table 6 shows that 47 percent of first poverty spells have an elapsed duration of one year and this percentage increases up to 54 per cent if we are in a second occurrence and to 73 per cent in a third one, meaning that if one has a second or third poverty spell, these spells are likely to be particularly short, in fact they are most likely to be one year periods. A similar result is obtained for non-poverty spells. In sum, there seem to be certain groups of individuals that are particularly prone to exit and re-enter poverty experiencing a row of one to two year spells.

\section{[place Tables 5 and 6 around here]}

\footnotetext{
${ }^{31}$ This result could be affected by the seven year interview structure of the dataset.
} 


\section{The Econometric approach to measuring the exit and re-entry transition rates: a multi state multi-spell discrete time hazard model.}

The main aim of this paper is the estimation of the individual probability of leaving poverty taking account the effect across multiple spells of the current poverty spell, the occurrence of multiple-spells, the lagged poverty and non-poverty duration and also individual and household characteristics. For that purpose, we chose to use lifetable analysis and to estimate a multivariate discrete hazard rate model for the exit and re-entry hazards.

Our strategy consists in simultaneously estimating ${ }^{32}$ two hazard rates: one for leaving poverty and another one for returning (or re-entering) to it. We first choose to examine the persistence of poverty for individuals who are poor in 1994 and have consecutive interviews in the panel (second sample), rather than examining the incidence of poverty for the entire ECHP sample. Later, we will restrict our analysis to those individuals who become poor in 1995 (inflow sample or sample of new entrants) in order to understand the relevance of left-truncation on results.

In the hazard methodology, the probability of leaving poverty $h_{p i}$ (or non-poverty , " $\mathrm{h}_{\mathrm{ni}}$ ") ${ }^{33}$ may be defined as the limit of the conditional probability of a transition taking place in a small interval $d t$ after time $t$ if no transition occurs until $t$, when that interval approaches to zero. The exit rate is modelled by means of a multiplicative separable function of three terms: the baseline exit hazard, the covariates and unobserved heterogeneity.

Formally:

$$
h_{p i}\left(T_{\mathrm{pi}}, X_{p i}(t), \theta_{i}\right)=\lim _{d t \rightarrow 0} \frac{\operatorname{Pr}\left(\mathrm{t}+\mathrm{dt}>T_{\mathrm{pi}} \geq \mathrm{t}_{1}^{\prime} \mathrm{T}_{\mathrm{pi}} \geq \mathrm{t}\right)}{\mathrm{dt}}=\lambda_{0}\left(\mathrm{~T}_{\mathrm{pi}}\right) \exp \left\{\mathrm{X}_{\mathrm{pi}}\left(\mathrm{T}_{\mathrm{pi}}\right)^{\prime} \beta\right\} \theta_{i}
$$

In this equation, subscript $i$ indicates the individual and $p$ the period in poverty. The term $T_{p i}$ is the latent current duration of individual $i$ 's $p$ 'th poverty spell, $\lambda_{0}(t)$ is the interval-specific baseline hazard rate, which is unknown; $X_{p i}$ is a vector of time-

\footnotetext{
${ }^{32}$ We have performed our estimations in Stata 9.0.

${ }^{33}$ We here present the econometrics for the analysis for the probability of leaving poverty in order to simplify notation, however our analysis includes the estimation of both the probability of leaving and reentering poverty in an analogous way.
} 
invariant and time-varying covariates for individual $i, \beta$ is the vector of unknown parameters to be estimated, and finally $\theta_{i}$ captures unobserved individual characteristics that could affect the hazard but are unobservable in the data, such as social exclusion problems together with attitudes towards claiming benefits of finding a job, motivation, inherent ability, and so on.

Defining the probability of surviving through any interval $d t$ after having survived the preceding $j$ intervals as $\left(1-h_{p i}\right)$, the probability of ending a spell of poverty in the $p^{\text {th }}$ interval is given by the hazard function: ${ }^{34}$

$$
\mathrm{h}_{\mathrm{pi}}=\operatorname{Pr}\left[\mathrm{T}_{\mathrm{pi}}=\mathrm{t}\right]=\mathrm{h}_{\mathrm{pi}} \prod_{\mathrm{s}=1}^{\mathrm{tp}-1}\left(1-\mathrm{h}_{\mathrm{pi}}^{\mathrm{s}}\right)
$$

where $t p$ represents poverty duration. However, given that there are some poverty spells that continue to proceed at the end of the sample period, right censored spells also contribute to the likelihood. Their contribution can be expressed as: ${ }^{35}$

$$
\operatorname{Pr}\left[\mathrm{T}_{\mathrm{pi}}>\mathrm{t}\right]=\prod_{\mathrm{s}=1}^{\mathrm{t}}\left(1-\mathrm{h}_{\mathrm{pi}}^{\mathrm{s}}\right)
$$

As we are interested to incorporate in our analysis multiple spells in poverty and non-poverty, our likelihood function contains several components that capture multiple exits from poverty to non-poverty and viceversa. In particular the likelihood for any observed individual $i$ can be expressed as:

$$
\begin{aligned}
& \mathrm{L}_{\mathrm{i}}=\left\{\prod_{\mathrm{s}=1}^{\mathrm{tp} 1}\left(1-\mathrm{h}_{\mathrm{p} 1 \mathrm{i}}^{\mathrm{s}}\right)\right\}^{(1-\mathrm{d} 1 \mathrm{i})} \times\left\{\mathrm{h}_{\mathrm{p} 1 \mathrm{i}} \prod_{\mathrm{s}=1}^{\mathrm{tp} 1-1}\left(1-\mathrm{h}_{\mathrm{p} 1 \mathrm{~s}}^{\mathrm{s}}\right) \prod_{s=1}^{\mathrm{tr} 1}\left(1-h_{r 1 i}^{\mathrm{s}}\right)\right\}^{\mathrm{d} 1 \mathrm{i}(1-\mathrm{d} 2 \mathrm{i}))} \times \\
& \left\{\mathrm{h}_{\mathrm{p} 1 \mathrm{i}} \prod_{\mathrm{s}=1}^{\mathrm{tp} 1-1}\left(1-\mathrm{h}_{\mathrm{p} 1 \mathrm{i}}^{\mathrm{s}}\right) \times \mathrm{h}_{r 1} \prod_{s=1}^{\mathrm{tr} 1-1}\left(1-h_{r 1 i}^{\mathrm{s}}\right)\right\}^{\mathrm{d} 1 \mathrm{id} 2 \mathrm{i}} \times\left\{\mathrm{h}_{\mathrm{r} 1 \mathrm{i}} \prod_{\mathrm{s}=1}^{\mathrm{tr} 1-1}\left(1-\mathrm{h}_{\mathrm{r} 1 \mathrm{i}}^{\mathrm{s}}\right) \prod_{s=1}^{\mathrm{tp} 2}\left(1-h_{p 21 i}^{\mathrm{s}}\right)\right\}^{\mathrm{d} 2 \mathrm{i}(1-\mathrm{d} 3 \mathrm{i})} \times
\end{aligned}
$$

\footnotetext{
${ }^{34}$ We omit $\mathrm{t}, \mathrm{X}$ and $\theta$ to simplify notation.

${ }^{35}$ Similarly to the exit rate, the hazard rate for re-entry is given by an analogous expression (where $\mathrm{p}$ changes to $\mathrm{n}): h_{n i}\left(T_{\mathrm{ni}}, X_{n i}(t), \theta_{i}\right)=\lambda_{0}\left(\mathrm{~T}_{\mathrm{ni}}\right) \exp \left\{\mathrm{X}_{\mathrm{ni}}\left(\mathrm{T}_{\mathrm{ni}}\right)^{\prime} \beta\right\} \theta_{i}$. Thus the probability of ending a spell of non-poverty in the $n^{h}$ interval is given by: $\mathrm{h}_{\mathrm{ni}}=\operatorname{Pr}\left[\mathrm{T}_{\mathrm{ni}}=\mathrm{t}\right]=\mathrm{h}_{\mathrm{ni}} \prod_{\mathrm{s}=1}^{\mathrm{tn}-1}\left(1-\mathrm{h}_{\mathrm{ni}}^{\mathrm{s}}\right)$ and a contribution to the likelihood of non-poverty spells that continue to proceed at the end of the sample of $\operatorname{Pr}\left[\mathrm{T}_{\mathrm{ni}}>\mathrm{t}\right]=\prod_{\mathrm{s}=1}^{\mathrm{tn}}\left(1-\mathrm{h}_{\mathrm{ni}}^{\mathrm{s}}\right)$
} 


$$
\begin{aligned}
& \left\{\mathrm{h}_{\mathrm{r} 1 \mathrm{i}} \prod_{\mathrm{s}=1}^{\mathrm{tr} 1-1}\left(1-\mathrm{h}_{\mathrm{r} 1 \mathrm{i}}^{\mathrm{s}}\right) \times h_{p 2 i} \prod_{s=1}^{\mathrm{tp} 2-1}\left(1-h_{p 2 i}^{\mathrm{s}}\right)\right\}^{\mathrm{d} 2 \mathrm{id} 3 \mathrm{i}} \times\left\{\mathrm{h}_{\mathrm{p} 2 \mathrm{i}} \prod_{\mathrm{s}=1}^{\mathrm{tp} 2-1}\left(1-\mathrm{h}_{\mathrm{p} 2 \mathrm{i}}^{\mathrm{s}}\right) \prod_{s=1}^{t \mathrm{tr} 2}\left(1-h_{r 2 i}^{\mathrm{s}}\right)\right\}^{(1-\mathrm{d} 4 \mathrm{i}) \mathrm{d} 3 \mathrm{i}} \times \\
& \left\{\mathrm{h}_{\mathrm{p} 2 \mathrm{i}} \prod_{\mathrm{s}=1}^{\mathrm{tp} 2-1}\left(1-\mathrm{h}_{\mathrm{p} 2 \mathrm{i}}^{\mathrm{s}}\right) \times h_{r 2 i} \prod_{s=1}^{\mathrm{tr} 2-1}\left(1-h_{r 2 i}^{\mathrm{s}}\right)\right\}^{\mathrm{d} 4 \mathrm{id} 3 \mathrm{i}}
\end{aligned}
$$

Where $h_{p 1}$ and $h_{p 2}$ are discrete hazard rates for leaving poverty during her first and second poverty spell and $h_{r 1}$ and $h_{r 2}$ are discrete hazard rates for re-entering poverty during the corresponding periods out of poverty in between. Furthermore $t_{p 1}$ and $t_{p 2}$ represent poverty spell durations while $t_{r 1}$ and $t_{r 2}$ are the non-poverty spell durations once the first poverty spell ends ( $t_{r 1}$ takes place between the $t_{p 1}$ period and just before $t_{p 2}$ ) or the second one finishes ( $t_{r 2}$ takes places after $t_{p 2}$ ). Finally, $d_{1 i}, d_{2 i}, d_{3 i}, d_{4 i}$ are dummy variables that allow us to distinguish between censored and completed poverty and non-poverty spells.

In our estimations we tried using a semi-parametric approach (piecewise constant hazard) by specifying duration dummies for the baseline. This method is common in the literature given its flexibility (see Stevens, 1999; Devicenti, 2001; Alba-Ramirez et al., 2007), however, we finally choose to present here those results obtained using a quadratic form of duration as in Biewen (2006) given that our results from life-tables confirm the adequateness of this particular form of duration dependence. In order to take unobserved heterogeneity into account, a finite-mixture unobserved heterogeneity distribution with unknown support points is also considered ${ }^{36}$. Therefore, the likelihood function for individual $i$ is obtained by integrating the following conditional likelihood distribution:

$$
L_{i}(\beta, \theta, \gamma, \pi)=\prod_{s=1}^{s} L(\beta, \gamma \mid \theta=s) \pi(s)
$$

where $\theta$ are the location points, $\pi$ the probability associated to them, and $s$ the number of support points.

\footnotetext{
${ }^{36}$ Heckman and Singer (1984) demonstrate that standard parametric form assumptions for unobserved heterogeneity might be biased when the chosen distribution for the unobservable term is incorrect. For this reason, they solve this problem by assuming that unobserved heterogeneity is discretely distributed with unknown support points.
} 
Note here that the use of specific year or duration dummies as explanatory variables stems from the idea that it appears reasonable to think that there is something about the length of the period of time spent either in poverty or out of poverty that affects the probability of a household leaving or returning to this situation. This reasoning appears straightforward in clear-cut definitions of other possible individual states like unemployment, where the loss of human capital or the end of benefit reception while unemployed makes it reasonable to expect a different escape rate from unemployment as unemployment duration increases. Why would this be the case for the state of poverty?

In the case of poverty, the definition of state of poverty is not so clear-cut. The division between being poor or not is a thin line in the income distribution. Is it reasonable then to expect that the opportunities to move up in the income distribution for households in its lowest tail will be affected by the time they remain in low income? Theoretically, when a household enters poverty, household members would start to use up their savings in order to maintain their previous level of welfare. The longer the household is poor, the more likely the household's savings will have ended and the more likely the household is to suffer a welfare loss. This welfare loss may imply a loss of household members' opportunities (due to the costs of undertaking them) that may bring the household out of poverty. These opportunities include the members' search for a job if unemployed, the members' investment in education that will help them enter the labour market in an advantageous position or the departure of members from the household to create a new one. Other effects on the exit hazard rate could be imposed by the means-testing and receipt duration schemes of state benefits paid to the lowest tail of the income distribution. Hence, it would be reasonable to think that the probability that a household jumps out of the lowest tail of the income distribution could be affected by poverty duration.

A similar reasoning would apply to the probability of returning to poverty. As Gardiner and Hills (1999) point out, the income mobility process is not random and low-income escapers are more likely to drop back into the poorest than those who never suffered low-income. Clearly, duration out of poverty in this case is expected to play a similar role: the longer the time the individual is out of poverty, the lower the probability of returning to it. 
The study of the relationship between the duration of a poverty spell and the escape and re-entry rate will test this correlation and find out if it is constant in time or it changes after some duration of a poverty or non poverty spell. Obviously, one should note that, in the case of poverty-non-poverty, the difficulties in detecting this correlation and disentangling it from unobserved heterogeneity may be larger than for other definitions of individual or household states. The reason is the larger amount of events that affect the value of the household income and the time span needed in order to detect this correlation due to both the time it takes a household to use up its savings and the long-term nature of the effects of a household's low income period on most household members' labour market opportunities and correlated decisions.

The covariates included in our estimations will try to capture the differences in individual characteristics but also those related to the composition of the household they belong to (number of adults in the household, number of dependent children, age and education of the household head, number of earners in the household, etc.) and household members labour market attachment (whether the household head or other adults are in paid work, etc.). The only individual variable included is gender while age will probably be captured by the age of the household head. To study differences in poverty exits, entries and re-entries with respect to the labour market conditions in which individuals live, we will, for now, only include yearly dummies. We hope that these dummies will serve as a control for the potential effect of the business cycle on poverty exit and re-entry.

\section{Results.}

In a first approach to measuring the relevance of spell duration on the probability of leaving poverty we report life-table estimates of the probability of leaving and reentering poverty. These results assume that the population is homogeneous in characteristics. We begin by analysing the whole sample of spells irrespective of their order and follow by distinguishing the order of each spell occurrence. In a second step we report results on estimations of transition rates using multivariate hazard regression models. This second approach to measuring transition risk provides a generalization of 
life tables estimations when transition rates are allowed to vary not only with the elapsed time at risk but also with observed and unobserved individual characteristics.

\subsection{Life-table estimates of transition rates.}

Tables 7 and 8 display the life-table estimates of hazard rates, survival probability and cumulative failure. Table 7 illustrates that both types of spells show a decline of the transition hazard as duration evolves, thus supporting the idea of negative duration dependence for both situations. However, some differences are already observable between the exit and re-entry hazards. First, the probability of returning to poverty is significantly lower than the probability of exiting from poverty. Thus, non-poverty spells, in general are of a longer duration than poverty spells. Secondly, the re-entry hazard continues to decline after three years of spell evolution while the exit hazard rate experiences a rapid decline during the first three years but is fairly constant from then onwards. Also, lagged durations have the expected sign: lagged poverty duration reduces the probability of leaving a poverty spell and lagged non-poverty durations decreases the probability of re-entering poverty when in a second non-poverty spell.

Distinguishing the order of spells and thus analysing the effects of spell accumulation is one our main objectives. Therefore, in Table 8 we include results on transition rates for each spell type by their order of occurrence. We can see that the results in Table 7 are similar to those obtained for the first spell of poverty or nonpoverty in Table 8 but are clearly different from those obtained for the second poverty spell. This result underlines the importance of taking multiple spells into account and in considering the differential hazard rate implied by accumulation of multiple experiences in and out of poverty.

Regarding the results for the first poverty spell, we can see that hazard rates decline rapidly during the first two years of observed poverty spell duration, thus supporting the idea of negative duration dependence. However, the hazard stays fairly constant from two up to seven years duration. Indeed, some 47 per cent of individuals in their first poverty spell left after one year of observation in the panel (note here that the real spell could be much longer) while out of those that remain poor, just over a third 32 per cent left poverty in the following year. In contrast, from the third to the sixth year of 
observation, the exit hazard rate fell only by two percentage points, from 23.5 to 21.4. Combining this relative high hazard rates for the first poverty spell with the results on the first spell survival function suggests that the majority of individuals in our sample experience relatively short poverty spells while some minority (a fifth of the sample) experience relatively long spells: 62 per cent of individuals remain poor only during one year, 44 per cent two years, 35 per cent at least 3 years and just about 19 per cent seven or more years.

\section{[place Tables 7 and 8 around here]}

The interesting question we pose is: Do these conclusions differ for those individuals that experience a second occurrence in poverty (after having experienced a period of non-poverty)? We observe that the probability that an individual leaves poverty when experiencing a second occurrence is significantly higher than it was during his/her first poverty spell. Indeed, during the first year the hazard rate in the second poverty period is 5.5 percentage points higher than in the first one. Interestingly this difference increases up to a 14 and 19 per cent more during the second and third year. Therefore, we find evidence that individuals remain a relatively shorter time in poverty if they have managed to leave deprivation for some time most recently.

Turning to results on non-poverty spells, we observe that the shape of the first reentry hazard is also consistent with negative duration dependence up to the third year, remaining constant thereafter. Interestingly we find little differences in the annual hazard rates of returning to poverty depending on the order of the non-poverty spell. The largest difference is observable after durations of three years or more and, in contrast with the impact of spell order in poverty experiences, poverty hazard rates in the second non-poverty spell are lower than in the first one. This implies that once you have managed to step out of poverty once, the accumulation of non-poverty spells plays in your favour by reducing the probability of coming back to poverty.

\subsection{The main characteristics of individuals under analysis.}


In any case, before going into a more detailed multivariate analysis of spells we must focus our discussion on the comparative characteristics of the samples of spells to be used in regressions. In order to do this we have constructed Table 9 where one can compare the characteristics of the pooled sample of individuals who experience some poverty spell (all spells sample, first column) with the sample of left-censored spells (first spells, second column) and with the sample of individuals whose transition into poverty is observed (inflow sample of spells, fourth column). ${ }^{37}$

Results show that characteristics of the pooled sample of individuals touched by poverty are very similar to those of the sample of left-censored poverty spells. ${ }^{38}$ As it could be expected, the largest differences in characteristics appear between individuals who suffer some left-censored poverty spell and those who are observed to enter poverty within the observation window. In particular, these differences are related to the household and household's head socioeconomic and demographic characteristics more than to individual characteristics, even if the individual's age and labour status is different too. In fact, if we were to use a sample of new entrants to poverty, thus omitting left-censored spells, our sample would contain significantly younger individuals, more often active, living in households whose head is relatively younger (often below 49 years of age), more educated, more often employed full time or unemployed but rarely retired, with more adults in the household (more often active in the labour market) and fewer children, whose main income source is often wages and whose total household income is somewhat nearer to the poverty line and, in some cases, it is declared to be temporarily zero. As it could be expected, the characteristics of the sample of new entrants are most similar to those of individuals who experience a second poverty spell within the observation window. ${ }^{39}$

\footnotetext{
${ }^{37}$ Note that an extended version of this table appears in Table A5. Note also that right censoring may imply also that the complete duration is not observed. We here refer to the observation of the complete spell since it begun until it finishes or suffers from attrition.

${ }^{38}$ Clearly this is due to the fact that most individuals suffering a poverty spell suffer just one left-censored spell.

${ }^{39}$ Our results here suggest that, similarly to what we obtained previously, transitory poverty in Spain is largely made up of the working-age population. Note in the OECD (2001) report Spain registers one of the largest percentages of individuals who are touched by poverty together with Greece, Italy and Portugal. However, Spain registers the largest percentage of this group if one restricts the analysis to the working-age population.
} 
Focusing on poverty spell duration, we can see that the elapsed duration of poverty spells for left-censored spells is significantly longer: 2.4 years compared to 1.7 years (more than eight months longer). This result clearly reflects the duration bias of choosing to discard left-censored spells completely when analysing poverty dynamics. Including the first and second spell in the analysis reduces duration to 2.2 years and includes non-poverty spells of a mean duration of 1.7 years in between poverty spells.

In general, after these descriptive analyses of our samples, we can assert that the inclusion of left-censored spells in the regressions will influence multivariate results on first-spell hazard rates for the case of Spain by including individuals who have experienced poverty more persistently, are older and often detached from the labour market. These effects will not appear in the analysis of their second spells where we will be including individuals who are more likely to fluctuate between poverty and nonpoverty (the transitorily poor) and whose results will most likely match those from a sample of new-entrants to a poverty situation.

$$
\text { [place Table } 9 \text { around here] }
$$

\subsection{Multivariate models of poverty exit and re-entry.}

In this sub-section, we estimate several discrete hazard models taking into account the individual's complete poverty history in order to analyse the determinants of leaving or re-entering poverty in Spain. We are interested in obtaining the evolution of the hazard rates as poverty and non-poverty spells evolve after controlling by personal, socio-economic and household characteristics as well as lagged poverty durations and unobserved heterogeneity. Table 10 presents the estimated hazard regressions for all exits and re-entries controlling for unobserved heterogeneity and distinguishing the spell order, therefore considering that exits and re-entry periods are not independent. 
However, we estimated also other regressions without controlling for unobserved heterogeneity and assuming spell order independence which are not reported here. ${ }^{40}$

The models considered include covariates such as sex, age, education, number of adults in the household, head job positions, head qualifications, household composition distinguishing single parents and households with dependent children, number of earners in the household, the length of the current poverty and non-poverty spell and the duration of the lagged poverty spells. ${ }^{41}$

As one would expect, Table 10 confirms that effects of a given covariate on poverty exit and re-entry have the opposite sign in most cases. Thus, characteristics that help in leaving poverty also help in avoiding recurrence. Exit rates from poverty are higher if the household's head has a high educational attainment or there is a large number of adults in the household, especially earners.

However, there are variables that present interesting differences in their effects depending on the number of accumulated spells experienced by individuals. For individuals in their first observed poverty spell (many of them left-censored), we find some negative duration dependence from the first year of spell duration ${ }^{42}$, while for those experiencing a second spell, the effect of duration is very different. Indeed, the probability of leaving a second poverty spell increases (even if less and less each year) at the beginning of the spell (approximately during three years), and from then after, the probability of leaving poverty starts to decrease as duration evolves. This pattern could be explained by the fact that first spells are often left-censored and may have lasted more than three years already at their first observation year. Surprisingly, however, if we use the sample of new entrants (see Table 16), first spells do not show the same pattern as second poverty spells did in our main sample, which may indicate that it

\footnotetext{
${ }^{40}$ We choose such a specification because the estimations that include unobserved heterogeneity show that it has a statistically significant effect on hazards. Further, considering the order of occurrence while estimating multiple spells jointly shows that some variables such as number of adults in the household, level of education of the head and current poverty duration present coefficients with a similar sign but with a rather different magnitude.

${ }^{41}$ We fitted a variety of other alternative specifications. For example, we considered including unemployment rates and GDP growth rate instead of yearly dummies but they were not statistically significant and the distribution of the estimated parameters was very imprecise. Therefore, these covariates we not kept in the specifications reported here.

${ }^{42}$ Biewen (2003) finds similar negative duration effects for German individuals.
} 
could be the case that individuals observed to enter poverty within the observation window for the first time are a somewhat particular type of individuals in their duration patterns.

Table 10 also shows that individuals who experience poverty are more likely to experience poverty in future because we observe that the longer the previous poverty duration the less likely individuals will leave a second poverty spell. Therefore, there is some state dependence poverty effect ${ }^{43}$ in individuals' poverty histories. Alternatively, the duration out of poverty plays a similar role: the longer the time the individual is out of poverty, the lower the probability of returning to it.

Another difference between the variables that help leaving poverty when spells accumulate is that being a male significantly increases the individual's probability of leaving poverty (a 10.5 percent) only for those experiencing their first spell (all leftcensored, by definition) while for individuals who are observed to fluctuate into and out of poverty at least twice during the observation window, gender does not affect their chances to leave poverty. ${ }^{44}$

Interestingly household composition covariates have a particularly strong effect on re-entries while, even if significant, they have smaller coefficients in exits. One person households have a significantly lower probability of re-entering poverty compared to couples with three or more children. Single parents and couples with one child are more likely to leave poverty and not to re-enter it soon compared to couples with three or more children who appear to be suffering a more persistent poverty experience.

Household head age variables turn out to have a significantly different effect on poverty exits by spell order. If we estimate multiple spells jointly in a pool of poverty periods, thus we do not distinguish the order of the spell, young children and adults, especially those whose household head is below 30 years of age show a significantly

\footnotetext{
${ }^{43}$ This effect is also detected by Biewen (2004) in Germany. The explanations are twofold. On one hand, individuals who are poor in one period have observed characteristics such as human capital decay, unemployment, health problems or difficult living arrangements that make poverty prone. On the other hand, they present unobserved heterogeneity terms such as lack of intelligence or ability, low levels of motivation or unfavourable attitudes.

${ }^{44}$ Obviously, one should check if this is also the case when including non-left-censored spells only in the estimation.
} 
higher probability of leaving poverty compared to the rest. However, the distinction of first and second poverty spells shows that this advantageous situation of youths disappears if individuals are fluctuating often between poverty and non-poverty. Indeed, only in first poverty spells individuals below 30 years of age show a higher probability of leaving poverty in comparison with those in their thirties or forties. In contrast, for those in their second poverty spell, head of household's age does not have a significant effect on the exit hazard rate.

\section{[place Figures 2 and 3 around here]}

Figures 2 and 3 present the comparison of hazard rates using a life-table homogeneous methodology and that estimated in a heterogeneous discrete-time recurrent hazard analysis. ${ }^{45}$ Comparing both types of analysis, we clearly appreciate that controlling for observed heterogeneity changes the common estimated hazard function by spell order. Furthermore, if the information on the different spell order were not included, the poverty hazard function would decline faster than it should for spells observed to begin within the observation window and the re-entry hazard function would decline slower than it should. In particular for the first poverty spell, the heterogeneous model significantly reduces the hazard during the first two or three years while this is not the case if durations reach 4 or 5 years. We observe that there is a common pattern in all the estimated hazard functions and life tables, however, thanks to the separate estimations by spell order, we observe that: (1) first poverty exits and all exits present a similar pattern and (2) the size of the second poverty exit rate is higher than that of the first poverty exit during the first three years of spell duration.

\section{[place Figure 4 around here]}

Figure 4 repeats the graphical analysis in Figures 2 and 3 (life-tables and estimated hazard function) including unobserved heterogeneity (non-poverty spells) and

\footnotetext{
${ }^{45}$ This figure and the next plots the estimated or predicted poverty hazard rates for all poverty exit spells and by the order of each poverty exit spell according to the estimations not reported here. The estimated hazard rates are calculated at the mean of covariates for all individuals. This figure shows the estimated hazard rate (after controlling for observed heterogeneity) at the mean values of covariates for all individuals. We also present Life-Table estimations of the poverty hazard rates, which may be interpreted as a type of sample-average hazard function without controlling for individual characteristics.
} 
thus presents the estimated hazard rates calculated using the estimations of Table 10 at the mean of covariates for all individuals. We observe here that, for the case of re-entry, the estimations including observed and unobserved heterogeneity and taking into account spell order shift down the probability of re-entering poverty when spells accumulate (i.e. the second non-poverty spell observed). Thus, the probability of reentering poverty in a second period does not grow when the non-poverty spell is still short (as it happens with poverty spells) it is always lower as the spell duration increases.

\subsection{Multivariate models of poverty exits and re-entry: only new entrants.}

The above discussion assumes that the poverty duration of all spells is known. This assumption is not true for many individuals because, by definition, all our first spells are left-censored. With this sample selection we have that for an important number of spells in our analysis we do not know how long a spell has been in progress.

We have only controlled for left-censoring by estimating the exit hazard of lefttruncated spells separately from the rest. ${ }^{46}$ In this section we perform some check of our main results using a sample of new entrants to poverty in 1995 and following their future movements out and into to poverty across the period 1995-2000.

Results on spell duration pooling the data for all the poverty and non-poverty periods without considering this second sample are reported in Table 11. The last row of this Table reflects that, as it would be expected, persistence of poverty when we choose to use only non-left-censored spells drops to 4.6 (from 9.4. We find that only 12 per cent of the individuals remain four years or more in poverty.

\section{[place Table 11 around here]}

\footnotetext{
${ }^{46}$ Note that is common practice to ignore the existence of left-censored spells in many poverty dynamics analysis. However, it should be noted that Heckman and Singer (1984) indicate that the estimations of models ignoring unobserved heterogeneity or omitted variables with only spells that begin after the start of the sample give consistent estimates of poverty transition rates for the population. In any case, Stevens (1999) indicates that erasing spells in progress at the start of the sample provokes a form of sample selection bias. Thus, this author asserts that considering individuals who begin a new spell after the start window period is likely to have higher transition probabilities than the entire population because they would have experienced at least one transition since the start window period.
} 
Tables 12 and 13 focus on the frequency distribution of elapsed poverty and nonpoverty spells by order of occurrence of the particular spell. Our findings in these tables highlight that when we select non-left-censored spells, recurrence is more likely: out of the 1,135 individuals who are enter poverty since 1995, 35 percent have two occurrences along the time of observation (compared to the 27 per cent of the previous sample). ${ }^{47}$ This implies that a 38 percent of the individuals re-enter poverty during the seven year period and more than 2.5 percent re-enter twice. In terms of duration, firstspells have a mean duration of 1.7 years, similar to that of second spells (1.6 years) while the duration of third poverty spells is slightly shorter (1.5 years). ${ }^{48}$

Indeed, Table 13 shows that 67 percent of first poverty spells have an elapsed duration of one year and this percentage, instead of increasing as in the previous sample, drops to 59 per cent if we are in a second occurrence. The percentage drops slightly more, to a 53 per cent, in a third spell, meaning that if one has a second or third poverty spell, these are likely to be somewhat longer than the first spell. In contrast, the probability of leaving a non-poverty spell tends to increase as spells accumulate. In sum, if we select those individuals that step into poverty, recurrence is of a "different type”, in terms that individuals seem to be beginning their experience in poverty and thus, are more prone to remain in it as spells accumulate.

[place Tables 12 and 13 around here]

Tables 14 and 15 display the life-table estimates of hazard rates, survival probability and cumulative failure for this second sample. Table 14 illustrates that both types of spells show a decline of the transition hazard as duration evolves, thus supporting the idea of negative duration dependence for both situations. However, some differences are already observable between the exit and re-entry hazards. First, the probability of returning to poverty is now much lower than the probability of exiting from poverty. Thus, non-poverty spells, in general are of a much longer duration than poverty spells for this particular group. Secondly, both the entry and the re-entry hazard

\footnotetext{
${ }^{47}$ Note however that, most probably due to the limited length of the panel, only 2.5 per cent (in comparison with 7.5 per cent) have three or more occurrences.

${ }^{48}$ This result could be affected by the seven year interview structure of the dataset.
} 
decline strongly after 1 year while declining much less from then onwards. This implies that some part of these individuals suffer a type of transitory and recurrent poverty which could be classified as "fluctuating".

Distinguishing the order of spells and thus analysing the effects of spell accumulation is one our main objectives. Therefore, in Table 15 we include results on transition rates for each spell type by their order of occurrence. We can see that the results in Table 14 are similar to those obtained for the first spell of poverty or nonpoverty in Table 15 but are clearly different from those obtained for the second poverty spell. Further, we should note that second poverty spells in this sample have a much lower hazard rate than second poverty spells in the first sample, which confirms the idea that, for this group of individuals, recurrence, if the second poverty spell lasts more than one year, may imply larger durations than it did for those in our first sample.

\section{[place Tables 14 and 15 around here]}

Do these conclusions make our results change regarding the implications of experiencing a second occurrence in poverty (after having experienced a period of nonpoverty)? We observe that the probability that someone is able to leave poverty when experiencing a second occurrence is now significantly lower than it was during his/her first poverty spell. Indeed, during the first year the hazard rate in the second poverty period is 30 percentage points lower than in the first one, even if the difference drops to 19 per cent and 4 per cent respectively during the second and third year. Thus, we find evidence that if we select individuals who have a had a transition into poverty in order to analyse dynamics, it is likely that the probability of leaving poverty for this group will be higher than otherwise only during the first poverty spell (especially the first year). This hazard will be significantly lower in subsequent spells if the household manages to step out of poverty relatively soon.

Finally, in Table 16 we present results of the estimation of a hazard model with this sample of spells, using the same specification as that in Table 10. Results indicate that negative duration dependence still holds for first poverty spells, thus individuals who experience poverty are more likely to experience poverty in future also using this sample. Further, leaving a second poverty spell is less likely if one has experienced a 
previous poverty and more the longer that period was. Therefore, we confirm the previous result on the existence of some state dependence effect in individuals' poverty histories.

Regarding the effect of covariates, results are fairly similar, even if less significant due to the reduction in the sample, to those in Table 10. In particular, the head of household education and labour market situation is determinant for exits and re-entries and household composition continues to have a particularly strong influence on reentries.

\section{Conclusions}

This paper analyses the effect of spell recurrence on poverty dynamics taking into account multiple poverty and non-poverty spells (the complete poverty history) and incorporating individual and household characteristics as well as unobserved heterogeneity. In particular, we investigate if the probability of experiencing a poverty transition is significantly different when the length of the current and past poverty spells changes. For that purpose we use a sample of Spanish individuals who are poor in 1994 and follow their future movements into and out of poverty across the period 1994-2001.

First of all, our findings highlight the importance of considering multiple spells in the analysis of poverty dynamics: out of the 3,664 individuals who are in poverty since 1994, 27 percent have two occurrences along the time of observation and nearly 7.5 per cent have three or more occurrences. This implies that a 35 percent of the individuals reenter poverty during the seven year period and more than 7 percent re-enter twice or three times. Poverty and non-poverty first-spells have a mean duration of two and a half years. We also observe that 47 percent of first poverty spells have an elapsed duration of one year, this percentage increases up to 54 per cent if we are in a second occurrence and to 73 per cent in a third one. This means that if one has a second or third poverty spell, spells are likely to be particularly short, in fact they are most likely to be one year periods. A similar result is obtained for non-poverty spells. In sum, there seem to be a 
small group of individuals that are particularly prone to exit and re-enter poverty experiencing a row of one-year spells.

Secondly, we find that the probability of returning to poverty is significantly lower than the probability of exiting from poverty. Thus, non-poverty spells, in general are of a longer duration than poverty spells. Furthermore, the re-entry hazard continues to decline after three years of spell evolution while the exit hazard rate experiences a rapid decline during the first three years but is fairly constant from then onwards.

Our descriptive analysis already offers us some easily observable differences between the exit and re-entry hazards when spells are evaluated jointly compared to when spell order is taken into account. Thus, distinguishing the order of spells and analysing the effects of spell accumulation we can see that the results from joint estimation of the poverty exit hazard are similar to those obtained for the first spell of poverty but are somewhat different from those obtained for the second poverty spell. This result underlines the importance of considering different hazard rates when the individual accumulates multiple experiences in and out of poverty.

In particular, we observe that the probability that an individual steps out of poverty when experiencing a second occurrence is significantly higher than it was during his/her first poverty spell. The largest difference is observable after durations of three years or more. In contrast, re-entry hazard rates in the second non-poverty spell are lower than in the first one, which implies that once you have managed to step out of poverty once, the accumulation of non-poverty spells plays in your favour by reducing the probability of coming back to poverty.

Thirdly, our results confirm that the characteristics of poverty duration in Spain are significantly different for individuals living in a household whose head is workingage compared to the rest. Their mean annual poverty rate of is significantly higher than that of the rest but, in terms of dynamics, they have a similar chronic poverty level (approximately a 3 per cent of all individuals in the sample are always poor) and a larger percentage of transitory and recurrent poor individuals. 
Fourthly, our multivariate regressions confirm that the effect of a covariate on poverty exit and re-entry is the opposite in most cases. Thus, characteristics that help individuals in leaving poverty also help them in avoiding recurrence. The highest poverty exit rates are associated to individuals with shorter durations in poverty, who did not experience previous poverty spells, who have a large number of adults in their household and whose household head holds a high educational qualification. In general, we find some negative duration dependence both in leaving and re-entering poverty, even if, the effect is most significant in first poverty spells while in second poverty spells results show some positive duration dependence during the first three years of spell duration that changes to being negative after that period. Also, lagged durations have the expected sign: lagged poverty duration reduces the probability of leaving a poverty spell and lagged non-poverty durations decreases the probability of re-entering poverty in a second non-poverty spell.

Interestingly also the estimated coefficients capturing the effect of covariates on exit and re-entry hazard rates change in magnitude and significance when we separate spells by their order. Household composition turns out to have a particularly strong effect on re-entries, especially in second non-poverty spells. In contrast, these variables are not significant for determining the exit hazard in second poverty spells while for first poverty spells, even if significant, they show smaller coefficients. Those households in worst position are couples with three or more children who have a lower probability of stepping out of poverty and a higher probability of re-entering it after exit. Thus, they are more likely to suffer long-term poverty. In contrast, individuals in one person households, single parents and couples with one child have a significantly lower probability of re-entering poverty once they managed to step out of it.

Finally, we have tried to check the validity of our main results using a sample of spells which, by definition, is not left-censored. Results indicate that this sample is more likely to include individuals that are "fluctuating" between poverty and non-poverty often. Therefore, in this second sample, if second poverty spells last more than a year, the hazard after that moment is significantly smaller than it was in our first sample. This result puts forward evidence that shows that if we try to avoid the problems imposed by left-censoring by selecting a sample of individuals who have had a transition into 
poverty, it is likely that the probability of leaving poverty we will obtain will be higher than otherwise during a first spell (and especially for the first year). This hazard will be significantly lower is subsequent spells if the household manages to step out of poverty relatively soon. Regarding the effects of covariates, results are fairly similar than those obtained with our first sample, even if less significant due to a large sample reduction. In particular, the head of household education and labour market situation is determinant for exits and re-entries and household composition continues to have a particularly strong influence on re-entries. 


\section{References}

Aassve, A., S. Burgess, C. Propper, and M. Dickson (2005), Modelling Poverty by Not Modelling Poverty: A Simultaneous Hazard Approach to the UK, ISER Working paper $2005-26$.

Allison, P.D. (1982), Discrete-time Methods for the Analysis of Event Histories, Chapter 2 in Sociological Methodology 1982, S.Leinhardt (editor), pp.61-97, Jossey-Bass Publishers, San Francisco.

Arranz, J.M. and Muro, J., (2004), Recurrent unemployment, welfare benefits and heterogeneity, International Review of Applied Economics, Vol. 18, No 4, pp. 423-441.

Arranz, J.M. and Muro, J., (2007), Duration data models, unemployment benefit and bias, Applied Economics Letters, forthcoming.

Alba-Ramírez, A., Muñoz, and Arranz, J.M. (2007) Exits from unemployment: recall or new job, Labour Economics, forthcoming.

Ayala, L., Sastre, M. y Navarro, C. (2006), La attrition en el Panel de Hogares de la Unión Europea: ¿Cómo influye en la movilidad?, trabajo presentado en el XIII Encuentro de Economía Pública, Almería.

Bane, M.J. and D.T. Ellwood (1986), Slipping into and out of poverty: the dynamics of spells, Journal of Human Resources, 21(1), 1-23.

Bonnal, L. Fougere, D. and Serandon, A. (1997) Evaluating the impact of French Employment policies on individual labour market histories, Review of Economic Studies, 64, 683-713.

Bárcena E. y F. A. Cowell, (2006), Static and Dynamic Poverty in Spain, 1993-2000, STICERD - Distributional Analysis Research Programme Papers 77, Suntory and Toyota International Centres for Economics and Related Disciplines, LSE.

Biewen, M. (2004) Measuring State Dependence in Individual Poverty Status: Are there Feedback Effects to Employment Decisions and Household Composition?, Discussion Papers of DIW Berlin 429, DIW Berlin, German Institute for Economic Research.

Biewen, M. (2006), Who are the chronic poor? An econometric analysis of chronic poverty in Germany, Research on Economic Inequality, Vol. 13, pp. 31-62 
Blumen, I., Kogan, M. and McCarthy, P.J. (1955), The industrial mobility of labour as a probability process, Ithaca, N.Y.: Cornell University Press.

Burgess, S. y Propper, C. (1998), An Economic Model of Household Income Dynamics, with an Application to Poverty Dynamics among American Women, Casepaper 9, July, STICERD, London School of Economics and Political Science.

Callens, Croux and Avramov (2005), Poverty dynamics in Europe: A Multilevel discrete-time Recurrent Hazard Analysis, mimeo.

Cantó, O. (2002), Climbing out of poverty, Falling back in: Low incomes’ stability in Spain, Applied Economics, 34: 1903-1916.

Cantó, O. (2003), Finding out the routes to escape poverty: the relevance of demographic vs. labour market events in Spain, Review of Income and Wealth, series 49, number 4, pp: 569-589.

Cantó, O., Gradín, C. y Del Río, C. (2003), La evolución de la pobreza estática y dinámica en el periodo 1985-1995, Hacienda Pública Española / Revista de Economía Pública, Volumen 167-(4/2003): 87-119.

Cantó, O, Del Río, C. and Gradín, C. (2007), What helps households with children in leaving poverty?: Evidence from Spain, Research on Economic Inequality, Vol. 14, pp. 1-29.

Cappellari, L. and Jenkins, S.P. (2002), Modelling Low Income Transitions, IZA Discussion Papers 504, Institute for the Study of Labor (IZA).

Cappellari, L. and Jenkins, S.P. (2004), Modelling low income transitions, Journal of Applied Econometrics, 19: 593-610.

Devicienti, F. (2001), Poverty persistence in Britain: a multivariate analysis using the BHPS, 1991-1997, Journal of Economics, Supplement 9: 1-34.

Duncan, G.J., Gustafsson, B., Hauser, R., Schmauss, G., Messinger, H., Muffels, R. Nolan, B. and Ray, J.C. (1993), Poverty dynamics in eight countries, Journal of Population Economics, 6, 215-234.

Fertig, M. and Tamm, M. (2007), Always poor or never poor and nothing in between? Duration of child poverty in Germany, ECINEQ WP, number 59-2007.

Finnie, R. and Sweetman, A. (2003), Poverty dynamics: empirical evidence for Canada, Canadian Journal of Economics, Volume 36 Issue 2 Page 291. 
Fouarge, D. and Layte, R. (2005), Welfare regimes and poverty dynamics: the duration and recurrence of poverty spells in Europe, Journal of Social Policy, 34, 3, pp. 407-426.

Gardiner, K. and Hills, J. (1999), Policy implications of new data on income mobility, The Economic Journal, 109: F91-F111.

Hansen, J. and Wahlberg, R. (2004), Poverty Persistence in Sweden, IZA Discussion Paper, No. 1209.

Heckman, J. and Borjas, G.I. (1980) Does unemployment cause future unemployment? Definitions, questions and answers for a Continuous Time model of Heterogeneity and State Dependence, Economica, 47, 247-283.

Heckman, J. and Singer, B. (1984), Econometric Duration Analysis, Journal of Econometrics, 24, pp.63-132.

Hill (1981) Some Dynamic Aspects of Poverty, in Five Thousand American Families: Patterns of Economic Progress. Analyses of the first twelve years of the Panel Study of Income Dynamics, Vol IX.

Iceland, J. (1997), The dynamics of poverty spells and issues of left-censoring, PSC Report Series, University of Michigan, number 97-378.

Jarvis S. and Jenkins, S.P. (1996), Changing places: Income mobility and Poverty Dynamics in Britain, Working paper 96-19, ESRC Research Centre on MicroSocial Change.

Jenkins, S. P. (1995), Easy estimation methods for discrete-time duration models, Oxford Bulletin of Economics and Statistics, 57, 129-37.

Jenkins, S.P. and Rigg, J. (2001), The Dynamics of Poverty in Britain, Department for Work and Pensions, Research Report No 157.

Kalbfleisch, J.D. and Prentice, R.L. (1980), The Statistical Analysis of Failure Time Data, New York: John Wiley.

Lancaster, T. (1990), The Econometric Analysis of Transition Data, Econometric Society Monographs, Cambridge University Press.

Lillard, L.A. y Willis, R.J. (1978), Dynamic aspects of Earnings Mobility, Econometrica, 46: 985-1012. 
Moffitt and Rendall (1995) Cohort Trends in the Lifetime Distribution of Female Headship in the U.S., 1968-1985, Demography, Vol. 32, No. 3, August, pp 407424.

OECD (2001) Employment Outlook, June, Chapter 2: When money is tight: poverty dynamics in OECD countries.

Omori, Y. (1997), Stigma effects of Non-employment, Economic Inquiry, Vol. XXXV, April, 394-416.

Shorrocks, A. (1976) Income mobility and the Markov assumption, The Economic Journal, 86, 566-578.

Stevens, A.H. (1994), The Dynamics of Poverty Spells: Updating Bane and Ellwood, American Economic Review Papers and Proceedings, May.

Stevens, A.H. (1999), Climbing out of poverty, Falling back in. (Measuring the Persistence of Poverty over multiple Spells), Journal of Human Resources, 34, 557-588.

Trivedi, P.K. and Alexander, J.N. (1989) Reemployment probability and multiple unemployment spells: A partial likelihood approach, Journal of Business and Economic Statistics, July, 395-401.

Valletta, R.G. (2006) The ins and outs of poverty in advance economies: Government policy and poverty dynamics in Canada, Germany, Great Britain and the United States. 
TABLES AND GRAPHS

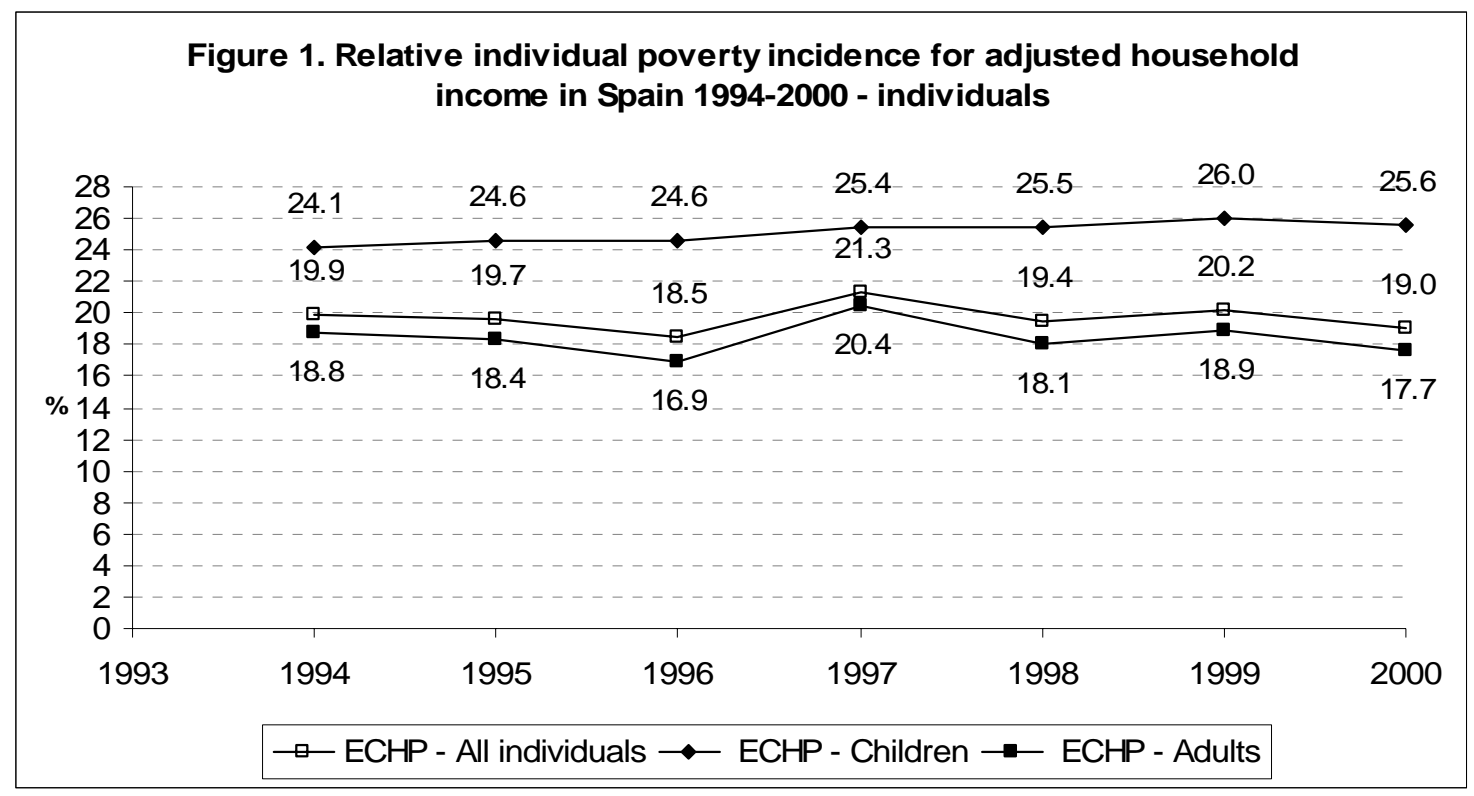

Note: These results are obtained using the ECHP using contemporary income and characteristics and a modified OECD scale. Calculations are made for individuals weighted by their population weight each particular year.

Table 1. Poverty Dynamics in Spain: some descriptive results. ECHP 1994-2000. Balanced Panel.

\begin{tabular}{|c|c|c|c|c|c|c|}
\hline & \multicolumn{3}{|c|}{ Working-age households } & \multicolumn{3}{|c|}{ Non-working age households } \\
\hline & \multirow[b]{2}{*}{ value } & \multicolumn{2}{|c|}{$\begin{array}{c}95 \% \text { confidence } \\
\text { interval }\end{array}$} & \multirow{2}{*}{$\begin{array}{l}\text { value } \\
\text { value }\end{array}$} & \multicolumn{2}{|c|}{$\begin{array}{c}95 \% \text { confidence } \\
\text { interval }\end{array}$} \\
\hline & & $\min$ & $\max$ & & $\min$ & $\max$ \\
\hline $\begin{array}{l}\text { Static poverty: } \\
\text { Annual poverty rate } \\
\text { (mean of the period) }\end{array}$ & 16.9 & - & - & 13.8 & - & - \\
\hline Chronic versus transitory poverty: & & & & & & \\
\hline Never poor & 51.8 & 50.3 & 53.3 & 60.5 & 57.6 & 63.6 \\
\hline Always poor & 3.0 & 2.6 & 3.4 & 3.3 & 2.6 & 4.1 \\
\hline Poor at least once & 45.2 & 43.7 & 46.6 & 36.1 & 33.4 & 39.2 \\
\hline Poor 5 out of 7 years & 11.2 & 10.4 & 12.1 & 8.5 & 7.2 & 9.8 \\
\hline Permanent-income poverty* & 15.4 & - & - & 11.6 & - & - \\
\hline Recurrent versus transitory poverty: & & & & & & \\
\hline One poverty spell & 60.3 & 58.4 & 62.3 & 72.9 & 69.2 & 76.3 \\
\hline Two poverty spells & 33.0 & 31.0 & 34.9 & 23.3 & 20.1 & 26.8 \\
\hline Three or more poverty spells & 6.6 & 5.8 & 7.6 & 3.8 & 2.3 & 5.5 \\
\hline One spell, left-censored & 14.5 & 13.1 & 16.0 & 16.6 & 13.3 & 20.3 \\
\hline Two spells, first left-censored & 10.9 & 9.6 & 12.3 & 4.4 & 3.0 & 5.9 \\
\hline Three or more spells, first left-censored & 5.9 & 5.1 & 6.9 & 2.3 & 1.3 & 3.5 \\
\hline \begin{tabular}{c|} 
First spell not left-censored \\
\end{tabular} & 68.6 & 66.7 & 70.4 & 76.6 & 72.8 & 79.9 \\
\hline
\end{tabular}

Note: These results are obtained for individuals present in all seven waves of the panel. The definition of working-age household is that in which the head of household is 15 to 64 years of age as in OECD (2001), measured at first interview in the panel. In all dynamic results we use last interview longitudinal weights while in static poverty calculations these are multiplied by crosssectional weights. Confidence intervals are obtained using bootstraps of 1000 repetitions and are bias corrected. Permanent-income 
poverty is calculated as the percentage of the sample for who average (equivalent) income over the seven years falls below the poverty line over this period.

* This indicator is calculated summing up all household incomes along the period and calculating the percentage of households whose total income in the seven-year period is below the $60 \%$ median income of the total sample during the whole period. 
Table 2. Poverty Incidence and Short-term Persistence.

ECHP 1994-2000. (weighted for attrition)

\begin{tabular}{|c|c|c|c|c|c|c|c|}
\hline & 1994 & 1995 & 1996 & 1997 & 1998 & 1999 & 2000 \\
\hline \multicolumn{8}{|l|}{ Incidence } \\
\hline Headcount index (\% poor) & 19.88 & 19.17 & 17.98 & 20.99 & 18.90 & 19.60 & 18.76 \\
\hline \multicolumn{8}{|c|}{ Conditional probabilities } \\
\hline \multicolumn{8}{|c|}{ Poverty short-term persistence } \\
\hline $\operatorname{Prob}\left(\mathrm{y}_{\mathrm{t}}=1 / \mathrm{y}_{\mathrm{t}-1}=1\right)$ & & 52.31 & 49.39 & 54.48 & 51.89 & 54.3 & 54.95 \\
\hline \multicolumn{8}{|l|}{ Poverty entry occurs } \\
\hline $\operatorname{Prob}\left(\mathrm{y}_{\mathrm{t}}=1 / \mathrm{y}_{\mathrm{t}-1}=0\right)$ & & 7.87 & 7.76 & 10.66 & 7.23 & 8.86 & 8.54 \\
\hline \multicolumn{8}{|l|}{ Poverty exit occurs } \\
\hline $\operatorname{Prob}\left(\mathrm{y}_{\mathrm{t}}=0 / \mathrm{y}_{\mathrm{t}-1}=1\right)$ & & 35.17 & 39.22 & 32.91 & 38.23 & 36.27 & 38.62 \\
\hline \multicolumn{8}{|l|}{ Persistence out of poverty } \\
\hline $\operatorname{Prob}\left(\mathrm{y}_{\mathrm{t}}=0 / \mathrm{y}_{\mathrm{t}-1}=0\right)$ & & 81.58 & 80.45 & 79.08 & 82.98 & 80.48 & 84.5 \\
\hline \multicolumn{8}{|l|}{ Atrittion } \\
\hline $\operatorname{Prob}\left(\mathrm{y}_{\mathrm{t}}=\mathrm{mis} / \mathrm{y}_{\mathrm{t}-1}=0\right)$ & & 10.54 & 11.79 & 10.27 & 9.79 & 10.66 & 6.96 \\
\hline $\operatorname{Prob}\left(\mathrm{y}_{\mathrm{t}}=\mathrm{mis} / \mathrm{y}_{\mathrm{t}-1}=1\right)$ & & 12.51 & 11.39 & 12.61 & 9.88 & 9.42 & 6.44 \\
\hline
\end{tabular}

\section{Table 3. Poverty Incidence and Short-term Persistence: Maximum observation window.}

Sample restricted to individuals who are poor in 1994 and consecutive observation in panel. ECHP 1994-2000. (weighted for attrition)

\begin{tabular}{lccccccc}
\hline & $\mathbf{1 9 9 4}$ & $\mathbf{1 9 9 5}$ & $\mathbf{1 9 9 6}$ & $\mathbf{1 9 9 7}$ & $\mathbf{1 9 9 8}$ & $\mathbf{1 9 9 9}$ & $\mathbf{2 0 0 0}$ \\
\hline Incidence & & & & & & & \\
\hline Headcount index (\% poor) & 100 & 59.98 & 51.35 & 52.94 & 51.36 & 45.58 & 40.39
\end{tabular}

\section{Conditional probabilities}

\begin{tabular}{|c|c|c|c|c|c|c|}
\hline \multicolumn{7}{|c|}{ Poverty short-term persistence } \\
\hline $\operatorname{Prob}\left(\mathrm{y}_{\mathrm{t}}=1 / \mathrm{y}_{\mathrm{t}-1}=1\right)$ & 53.87 & 60.42 & 65.29 & 68.06 & 58.03 & 61.08 \\
\hline \multicolumn{7}{|l|}{ Poverty entry occurs } \\
\hline $\operatorname{Prob}\left(\mathrm{y}_{\mathrm{t}}=1 / \mathrm{y}_{\mathrm{t}-1}=0\right)$ & & 24.2 & 29.83 & 24.72 & 22.96 & 19.15 \\
\hline \multicolumn{7}{|l|}{ Poverty exit occurs } \\
\hline $\operatorname{Prob}\left(\mathrm{y}_{\mathrm{t}}=0 / \mathrm{y}_{\mathrm{t}-1}=1\right)$ & 35.94 & 30.64 & 22.93 & 25.36 & 32.99 & 33.03 \\
\hline \multicolumn{7}{|c|}{ Persistence out of poverty } \\
\hline $\operatorname{Prob}\left(\mathrm{y}_{\mathrm{t}}=0 / \mathrm{y}_{\mathrm{t}-1}=0\right)$ & & 63.36 & 62.95 & 67.88 & 65.27 & 73.69 \\
\hline \multicolumn{7}{|l|}{ Atrittion } \\
\hline $\operatorname{Prob}\left(\mathrm{y}_{\mathrm{t}}=\mathrm{mis} / \mathrm{y}_{\mathrm{t}-1}=0\right)$ & & 12.44 & 7.22 & 7.4 & 11.78 & 7.15 \\
\hline $\operatorname{Prob}\left(\mathrm{y}_{\mathrm{t}}=\mathrm{mis} / \mathrm{y}_{\mathrm{t}-1}=1\right)$ & 10.19 & 8.94 & 11.78 & 6.58 & 8.98 & 5.89 \\
\hline
\end{tabular}

Note: These results are obtained using the ECHP contemporary income and characteristics information and using a modified OECD equivalence scale. Calculations of the headcound index are made for individuals weighted by their population weight each particular year. The sample here is that of all individuals poor in 1994 and in consecutive observation in the ECHP panel until the survey ends or they suffer from attrition. Note that $\mathrm{y}_{\mathrm{t}}=1$ if the individual is poor in time $t$ and 0 if the individual is non-poor, “mis"means attrition occurred between the two interviews 
Table 4. Frequency distributions of elapsed durations, all spells.

Sample restricted to individuals who are poor in 1994 and consecutive observation in panel. ECHP 1994-2000.

\begin{tabular}{ccccc}
\hline Elapsed duration & all poverty spells & \multicolumn{2}{c}{ All non-poverty spells } \\
\hline & Freq & $\mathbf{\%}$ & Freq & $\mathbf{\%}$ \\
\hline $\mathbf{1}$ & 1,395 & 38.1 & 865 & 35.5 \\
$\mathbf{2}$ & 796 & 21.7 & 549 & 22.5 \\
$\mathbf{3}$ & 514 & 14.0 & 361 & 14.8 \\
$\mathbf{4}$ & 277 & 7.6 & 232 & 9.5 \\
$\mathbf{5}$ & 214 & 5.8 & 145 & 5.9 \\
$\mathbf{6}$ & 123 & 3.4 & 288 & 11.8 \\
$\mathbf{7}$ & 345 & 9.4 & - & - \\
\hline Total individuals & 3,664 & 100 & 2,440 & 100 \\
\hline Mean (Std. Dev.) & $2.69(1.94)$ & \multicolumn{3}{c}{$2.63(1.70)$} \\
\hline
\end{tabular}

Table 5. Number of spells of poverty and non-poverty in total sample.

Sample restricted to individuals who are poor in 1994 and consecutive observation in panel. ECHP 1994-2000

\begin{tabular}{ccccc}
\hline Number of occurrences & \multicolumn{2}{c}{ Poverty } & \multicolumn{2}{c}{ Non-poverty } \\
\hline & Freq. & \% & Freq. & \% \\
\hline $\mathbf{1}$ & 2,388 & 65.17 & 1,670 & 45.58 \\
$\mathbf{2}$ & 1,003 & 27.37 & 678 & 18.5 \\
$\mathbf{3}$ & 268 & 7.31 & 92 & 2.51 \\
$\mathbf{4}$ & 5 & 0.14 & & \\
\hline Total individuals & 3,664 & 100 & 2,440 & 66.59 \\
\hline
\end{tabular}

Table 6. Frequency distributions of elapsed durations by order of occurrence. Sample restricted to individuals who are poor in 1994 and consecutive observation in panel.

\begin{tabular}{|c|c|c|c|c|c|c|c|c|c|c|c|c|}
\hline \multirow[t]{2}{*}{$\begin{array}{l}\text { Elapsed } \\
\text { duration }\end{array}$} & \multicolumn{2}{|c|}{$\begin{array}{c}\text { First poverty } \\
\text { spell }\end{array}$} & \multicolumn{2}{|c|}{$\begin{array}{c}\text { First non-poverty } \\
\text { spell }\end{array}$} & \multicolumn{2}{|c|}{$\begin{array}{c}\text { Second poverty } \\
\text { spell }\end{array}$} & \multicolumn{2}{|c|}{$\begin{array}{l}\text { Second non- } \\
\text { poverty spell }\end{array}$} & \multicolumn{2}{|c|}{$\begin{array}{l}\text { Third poverty } \\
\text { spell }\end{array}$} & \multicolumn{2}{|c|}{$\begin{array}{l}\text { Third non- } \\
\text { poverty spell }\end{array}$} \\
\hline & Freq & $\%$ & Freq & $\%$ & Freq & $\%$ & Freq & $\%$ & Freq & $\%$ & Freq & $\%$ \\
\hline 1 & 1,718 & 46.89 & 1085 & 44.47 & 691 & 54.15 & 413 & 53.64 & 201 & 73.63 & 81 & 88.04 \\
\hline 2 & 705 & 19.24 & 461 & 18.89 & 332 & 26.02 & 225 & 29.22 & 59 & 21.61 & 11 & 11.96 \\
\hline 3 & 389 & 10.62 & 276 & 11.31 & 146 & 11.44 & 85 & 11.04 & 13 & 4.76 & - & - \\
\hline 4 & 205 & 5.59 & 185 & 7.58 & 72 & 5.64 & 47 & 6.1 & - & - & - & - \\
\hline 5 & 179 & 4.89 & 145 & 5.94 & 35 & 2.74 & - & - & - & - & - & - \\
\hline 6 & 123 & 3.36 & 288 & 11.8 & - & - & - & - & - & - & - & - \\
\hline 7 & 345 & 9.42 & - & - & - & - & - & - & - & - & - & - \\
\hline $\begin{array}{c}\text { Total } \\
\text { individuals }\end{array}$ & 3,664 & 100 & 2440 & 100 & 1276 & 100 & 770 & 100 & 273 & 100 & 92 & 100 \\
\hline $\begin{array}{c}\text { Mean } \\
\text { (Std. Dev.) }\end{array}$ & \multicolumn{2}{|c|}{$\begin{array}{l}2.50 \\
(1.97)\end{array}$} & \multicolumn{2}{|c|}{$\begin{array}{l}2.47 \\
(1.75) \\
\end{array}$} & \multicolumn{2}{|c|}{$\begin{array}{l}1.77 \\
(1.04) \\
\end{array}$} & \multicolumn{2}{|c|}{$\begin{array}{c}1.70 \\
(0.89) \\
\end{array}$} & \multicolumn{2}{|c|}{$\begin{array}{c}1.31 \\
(0.56) \\
\end{array}$} & \multicolumn{2}{|c|}{$\begin{array}{l}1.12 \\
(0.33)\end{array}$} \\
\hline
\end{tabular}


Table 7. Life tables estimates of hazard rates, survival probability and cumulative failure for all poverty exits and re-entries.

Based on all poverty spells observed from ECHP waves 1994-2000 for individuals who are poor since 1994.

\begin{tabular}{cccccccccc}
\hline $\begin{array}{c}\text { Interval } \\
\text { (years) }\end{array}$ & $\begin{array}{c}\text { Total number of } \\
\text { individuals at risk } \\
\text { Total (individuals) }\end{array}$ & Deaths & Lost & Survival(\%) & $\begin{array}{c}\text { Cum. } \\
\text { (\%) }\end{array}$ & $\begin{array}{c}\text { Std. } \\
\text { Error }\end{array}$ & $\begin{array}{c}\text { Hazard } \\
\text { (\%) }\end{array}$ & $\begin{array}{c}\text { Std. } \\
\text { Error }\end{array}$ \\
\hline & & \multicolumn{7}{c}{ All exits } \\
\hline 1 & 2 & 5218 & 1900 & 715 & 60.91 & 39.09 & 0.7 & 48.59 & 1.08 \\
2 & 3 & 2603 & 718 & 378 & 42.79 & 57.21 & 0.75 & 34.94 & 1.28 \\
3 & 4 & 1507 & 323 & 225 & 32.88 & 67.12 & 0.75 & 26.2 & 1.45 \\
4 & 5 & 959 & 163 & 114 & 26.94 & 73.06 & 0.75 & 19.87 & 1.55 \\
5 & 6 & 682 & 111 & 103 & 22.2 & 77.8 & 0.74 & 19.3 & 1.82 \\
6 & 7 & 468 & 87 & 36 & 17.91 & 82.09 & 0.73 & 21.4 & 2.28 \\
7 & 8 & 345 & 0 & 345 & 17.91 & 82.09 & 0.73 & 0 & - \\
\hline & & & & All re-entries & & & & \\
\hline 1 & 2 & 3302 & 947 & 632 & 68.29 & 31.71 & 0.85 & 37.69 & 1.2 \\
2 & 3 & 1723 & 351 & 346 & 52.82 & 47.18 & 0.98 & 25.54 & 1.35 \\
3 & 4 & 1026 & 155 & 206 & 43.95 & 56.05 & 1.04 & 18.33 & 1.47 \\
4 & 5 & 665 & 63 & 169 & 39.18 & 60.82 & 1.09 & 11.48 & 1.44 \\
5 & 6 & 433 & 38 & 107 & 35.26 & 64.74 & 1.15 & 10.54 & 1.71 \\
6 & 7 & 288 & 0 & 288 & 35.26 & 64.74 & 1.15 & & \\
\hline
\end{tabular}

Table 8. Life tables estimates of hazard rates, survival probability and cumulative failure by order of occurrence.

Based on all poverty spells observed from ECHP waves 1994-2000 for individuals who are poor since 1994.

\begin{tabular}{|c|c|c|c|c|c|c|c|c|c|}
\hline \multicolumn{2}{|c|}{$\begin{array}{l}\text { Interval } \\
\text { (years) }\end{array}$} & $\begin{array}{l}\text { Total number of } \\
\text { individuals at risk }\end{array}$ & Deaths & Lost & $\begin{array}{c}\text { Survival } \\
(\%)\end{array}$ & $\begin{array}{c}\text { Cum. } \\
\text { Failure } \\
(\%)\end{array}$ & $\begin{array}{l}\text { Std. } \\
\text { Error }\end{array}$ & $\begin{array}{c}\text { Hazard } \\
(\%)\end{array}$ & $\begin{array}{l}\text { Std. } \\
\text { Error }\end{array}$ \\
\hline \multicolumn{10}{|c|}{ First poverty spell (1) } \\
\hline 1 & 2 & 3664 & 1326 & 392 & 61.76 & 38.24 & 0.83 & 47.27 & 1.26 \\
\hline 2 & 3 & 1946 & 519 & 186 & 44.47 & 55.53 & 0.88 & 32.57 & 1.41 \\
\hline 3 & 4 & 1241 & 246 & 143 & 35.11 & 64.89 & 0.87 & 23.51 & 1.49 \\
\hline 4 & 5 & 852 & 151 & 54 & 28.69 & 71.31 & 0.85 & 20.15 & 1.63 \\
\hline 5 & 6 & 647 & 111 & 68 & 23.49 & 76.51 & 0.83 & 19.91 & 1.88 \\
\hline 6 & 7 & 468 & 87 & 36 & 18.95 & 81.05 & 0.8 & 21.4 & 2.28 \\
\hline 7 & 8 & 345 & 0 & 345 & 18.95 & 81.05 & 0.8 & 0 & - \\
\hline \multicolumn{10}{|c|}{ First non-poverty spell (2) } \\
\hline 1 & 2 & 2440 & 736 & 349 & 67.51 & 32.49 & 0.98 & 38.79 & 1.4 \\
\hline 2 & 3 & 1355 & 295 & 166 & 51.86 & 48.14 & 1.1 & 26.23 & 1.51 \\
\hline 3 & 4 & 894 & 144 & 132 & 42.84 & 57.16 & 1.14 & 19.05 & 1.58 \\
\hline 4 & 5 & 618 & 63 & 122 & 37.99 & 62.01 & 1.16 & 11.99 & 1.51 \\
\hline 5 & 6 & 433 & 38 & 107 & 34.19 & 65.81 & 1.2 & 10.54 & 1.71 \\
\hline 6 & 7 & 288 & 0 & 288 & 34.19 & 65.81 & 1.2 & & \\
\hline \multicolumn{10}{|c|}{ Second poverty spell (3) } \\
\hline 1 & 2 & 1276 & 491 & 200 & 58.25 & 41.75 & 1.44 & 52.77 & 2.3 \\
\hline 2 & 3 & 585 & 190 & 142 & 36.72 & 63.28 & 1.54 & 45.35 & 3.2 \\
\hline 3 & 4 & 253 & 77 & 69 & 23.78 & 76.22 & 1.55 & 42.78 & 4.76 \\
\hline 4 & 5 & 107 & 12 & 60 & 20.07 & 79.93 & 1.64 & 16.9 & 4.86 \\
\hline 5 & 6 & 35 & 0 & 35 & 20.07 & 79.93 & 1.64 & & \\
\hline \multicolumn{10}{|c|}{ Second non-poverty spell (4) } \\
\hline 1 & 2 & 770 & 206 & 207 & 69.09 & 30.91 & 1.79 & 36.56 & 2.5 \\
\hline 2 & 3 & 357 & 56 & 169 & 54.89 & 45.11 & 2.21 & 22.9 & 3.04 \\
\hline
\end{tabular}




\begin{tabular}{|c|c|c|c|c|c|c|c|c|c|}
\hline 3 & 4 & 132 & 11 & 74 & 48.54 & 51.46 & 2.66 & 12.29 & 3.7 \\
\hline 4 & 5 & 47 & 0 & 47 & 48.54 & 51.46 & 2.66 & & \\
\hline \multicolumn{10}{|c|}{ Third poverty spell (5) } \\
\hline 1 & 2 & 273 & 83 & 118 & 61.21 & 38.79 & 3.33 & 48.12 & 5.13 \\
\hline 2 & 3 & 72 & 9 & 50 & 49.49 & 50.51 & 4.43 & 21.18 & 7.02 \\
\hline 3 & 4 & 13 & 0 & 13 & 49.49 & 50.51 & 4.43 & & \\
\hline \multicolumn{10}{|c|}{ Third non-poverty spell (6) } \\
\hline 1 & 2 & 92 & 5 & 76 & 90.74 & 9.26 & 3.94 & 9.71 & 4.34 \\
\hline 2 & 3 & 11 & 0 & 11 & 90.74 & 9.26 & 3.94 & & \\
\hline \multicolumn{10}{|c|}{ Fourth poverty spell (7) } \\
\hline 1 & 2 & 5 & 0 & 5 & 100 & 0 & 0 & & \\
\hline
\end{tabular}


Figure 2. Life-Table Hazard rates as duration evolves.

ECHP 1994-2000.

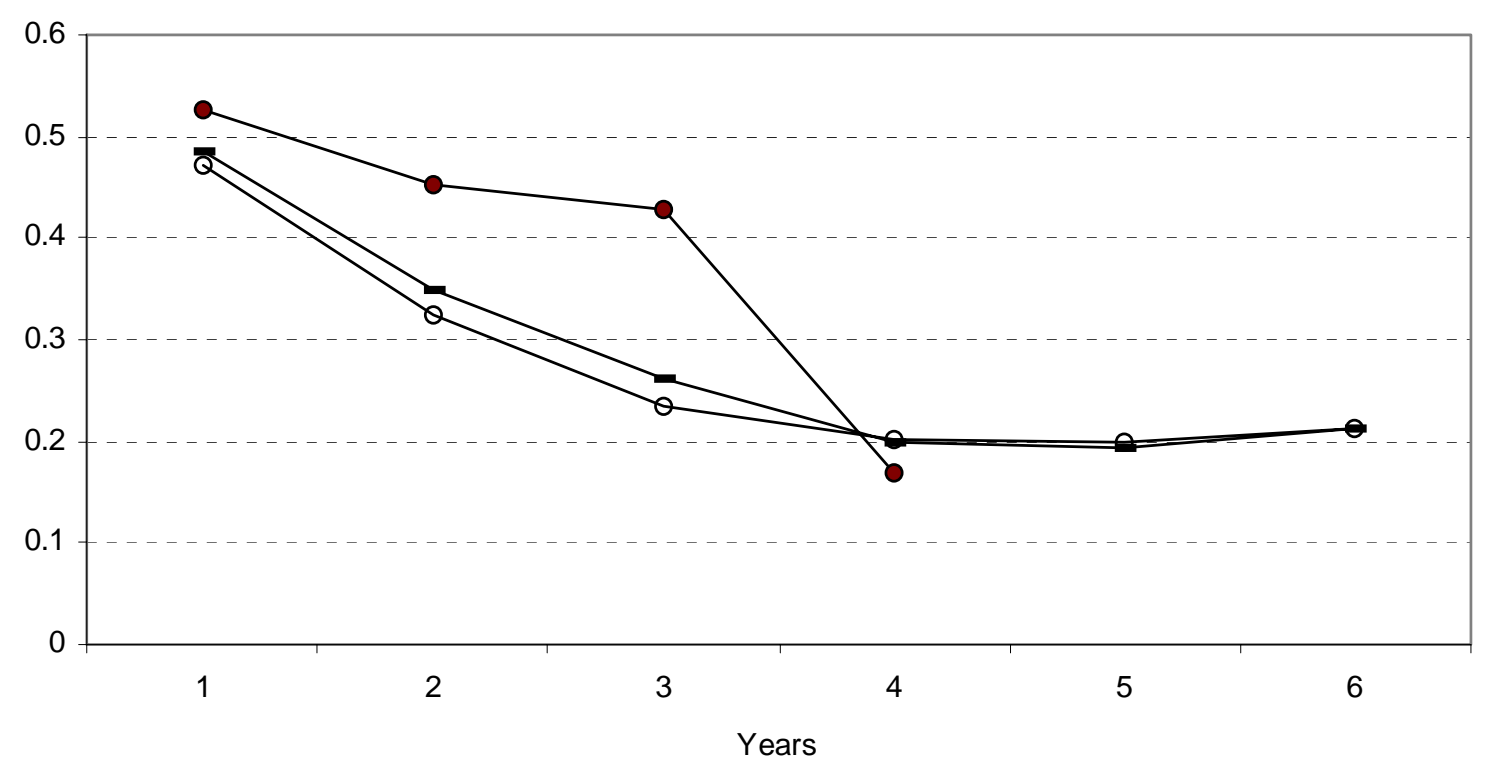

life tables (all exits) $\_$- life tables (first exit) $\multimap-1$ life tables (second exit) 
Figure 3. Life-Table Hazard rates as duration evolves, by spell order. ECHP 1994-2000.

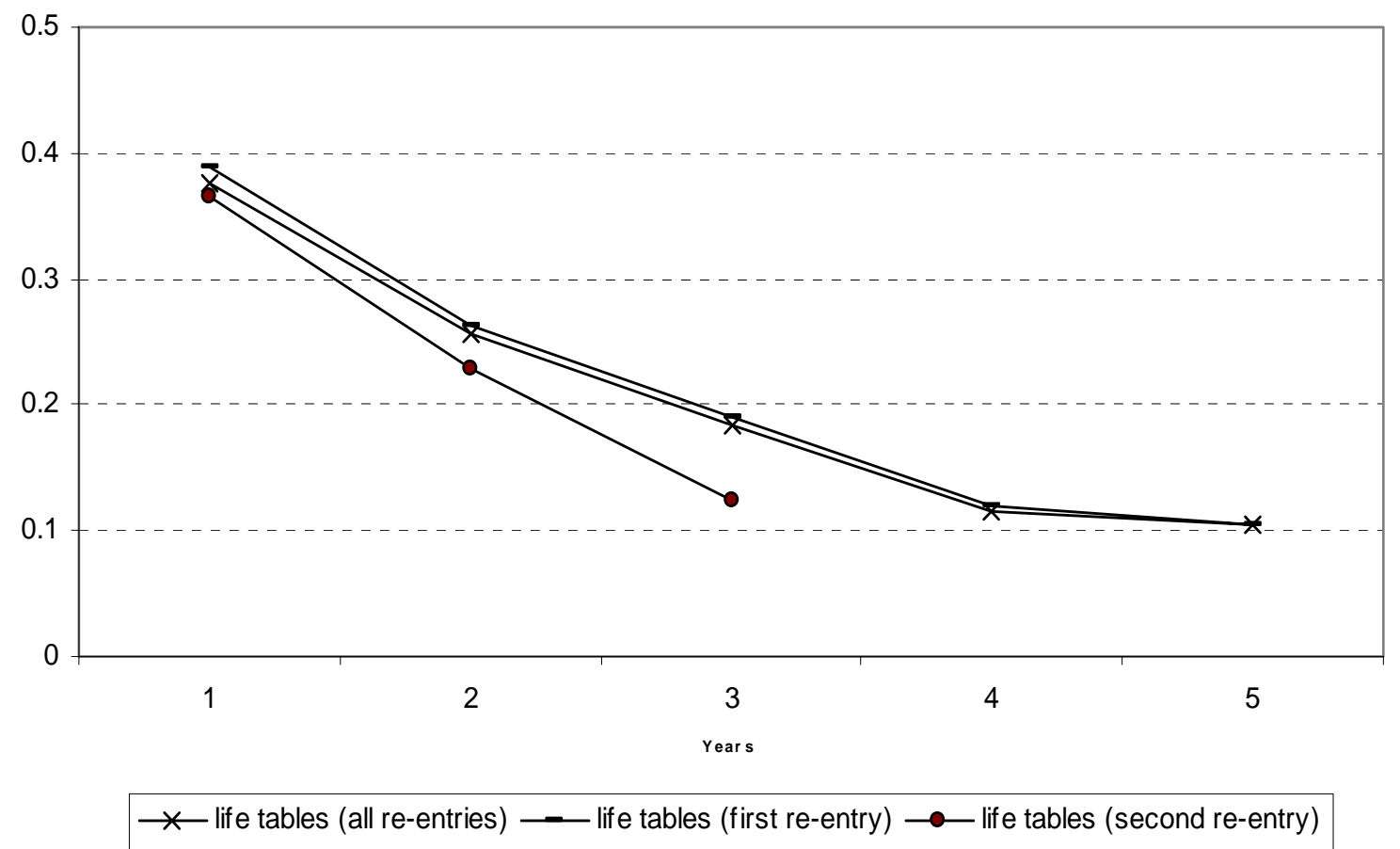


Table 9. Characteristics of spells samples, individuals: Means.

\begin{tabular}{|c|c|c|c|c|c|c|c|c|}
\hline \multirow[b]{2}{*}{ Characteristics } & \multicolumn{8}{|c|}{ POVERTY SPELLS } \\
\hline & \multicolumn{2}{|c|}{$\begin{array}{c}\text { All spells } \\
\\
\text { (5,218 indiv.) } \\
\text { (5,113 weight) }\end{array}$} & \multicolumn{2}{|c|}{$\begin{array}{c}\text { First spell } \\
\\
\text { (3,664 indiv.) } \\
\text { (3,387weight) } \\
\end{array}$} & \multicolumn{2}{|c|}{$\begin{array}{c}\text { Second spell } \\
\text { (1,276 indiv.) } \\
\text { (1,416 weight) } \\
\end{array}$} & \multicolumn{2}{|c|}{$\begin{array}{c}\text { Inflow sample of } \\
\text { spells - new entrants } \\
\text { (1,593 indiv.) } \\
\text { (1,632 weight) }\end{array}$} \\
\hline Individual Characteristics & Means & S.E. & Means & S.E. & Means & S.E. & Means & S.E. \\
\hline ( & 36.2 & 22.2 & 36.6 & 22.8 & 35.4 & 21.2 & 35.2 & 21.2 \\
\hline Aged 16-29 & 0.23 & 0.42 & 0.22 & 0.42 & 0.24 & 0.43 & 0.25 & 0.43 \\
\hline Aged 60+ & 0.18 & 0.39 & 0.20 & 0.40 & 0.16 & 0.37 & 0.16 & 0.37 \\
\hline Child, below 16 years old & 0.23 & 0.42 & 0.24 & 0.43 & 0.22 & 0.42 & 0.22 & 0.42 \\
\hline \multicolumn{9}{|l|}{ Labour status } \\
\hline Working (+15 hours/week) & 0.22 & 0.41 & 0.20 & 0.40 & 0.24 & 0.43 & 0.26 & 0.44 \\
\hline Working (less 15 hours/week) & 0.02 & 0.15 & 0.03 & 0.16 & 0.02 & 0.13 & 0.01 & 0.10 \\
\hline Unemployed & 0.14 & 0.35 & 0.15 & 0.35 & 0.13 & 0.34 & 0.14 & 0.34 \\
\hline Discouraged worker & 0.00 & 0.06 & 0.00 & 0.05 & 0.01 & 0.09 & 0.02 & 0.13 \\
\hline Economically inactive & 0.38 & 0.49 & 0.39 & 0.49 & 0.38 & 0.49 & 0.36 & 0.48 \\
\hline \multicolumn{9}{|l|}{ Unemployment experience } \\
\hline Had unemp. spell last 5 years & 0.29 & 0.45 & 0.29 & 0.45 & 0.30 & 0.46 & 0.31 & 0.46 \\
\hline \multicolumn{9}{|l|}{ Main income source } \\
\hline No income from any source & 0.28 & 0.45 & 0.28 & 0.45 & 0.29 & 0.46 & 0.27 & 0.44 \\
\hline Wages and salaries & 0.13 & 0.34 & 0.12 & 0.33 & 0.14 & 0.35 & 0.19 & 0.39 \\
\hline Self-employment or farming & 0.06 & 0.24 & 0.05 & 0.23 & 0.06 & 0.24 & 0.06 & 0.23 \\
\hline Pensions & 0.11 & 0.31 & 0.11 & 0.32 & 0.09 & 0.28 & 0.09 & 0.29 \\
\hline Unemployment benefits & 0.06 & 0.23 & 0.06 & 0.24 & 0.05 & 0.22 & 0.06 & 0.25 \\
\hline Any other social benefits & 0.08 & 0.27 & 0.08 & 0.27 & 0.08 & 0.27 & 0.06 & 0.24 \\
\hline Private income & 0.05 & 0.22 & 0.04 & 0.20 & 0.06 & 0.24 & 0.04 & 0.21 \\
\hline \multicolumn{9}{|l|}{ Household Characteristics } \\
\hline \multicolumn{9}{|l|}{ Household structure } \\
\hline Total household members & 4.16 & 1.68 & 4.09 & 1.69 & 4.27 & 1.63 & 4.17 & 1.59 \\
\hline Number of adults in household & 3.06 & 1.35 & 2.99 & 1.32 & 3.15 & 1.43 & 3.10 & 1.40 \\
\hline Number of $0-5$ children & 0.23 & 0.42 & 0.24 & 0.43 & 0.21 & 0.41 & 0.21 & 0.41 \\
\hline \multicolumn{9}{|l|}{ Main income source } \\
\hline Wages and salaries & 0.34 & 0.47 & 0.32 & 0.47 & 0.38 & 0.49 & 0.42 & 0.49 \\
\hline Self-employment income & 0.15 & 0.36 & 0.13 & 0.33 & 0.18 & 0.38 & 0.14 & 0.34 \\
\hline Pensions income & 0.23 & 0.42 & 0.25 & 0.43 & 0.20 & 0.40 & 0.21 & 0.41 \\
\hline Unemployment income & 0.12 & 0.33 & 0.14 & 0.35 & 0.10 & 0.30 & 0.13 & 0.34 \\
\hline Transfers income & 0.10 & 0.30 & 0.11 & 0.31 & 0.10 & 0.30 & 0.08 & 0.27 \\
\hline Private income & 0.05 & 0.21 & 0.05 & 0.22 & 0.04 & 0.19 & 0.03 & 0.16 \\
\hline \multicolumn{9}{|l|}{ Poverty Gap (as \% of poverty line) } \\
\hline $0-10 \%$ & 0.23 & 0.42 & 0.22 & 0.42 & 0.23 & 0.42 & 0.28 & 0.45 \\
\hline Zero income & 0.02 & 0.14 & 0.00 & 0.00 & 0.06 & 0.25 & 0.07 & 0.25 \\
\hline \multicolumn{9}{|l|}{ Household head characteristics } \\
\hline Household head aged 30-39 & 0.20 & 0.40 & 0.20 & 0.40 & 0.23 & 0.42 & 0.27 & 0.44 \\
\hline Household head aged 40-49 & 0.26 & 0.44 & 0.24 & 0.43 & 0.29 & 0.45 & 0.28 & 0.45 \\
\hline Household head aged 50-59 & 0.23 & 0.42 & 0.23 & 0.42 & 0.23 & 0.42 & 0.19 & 0.39 \\
\hline Household head aged 60+ & 0.24 & 0.43 & 0.29 & 0.45 & 0.16 & 0.36 & 0.12 & 0.33 \\
\hline Female household head & 0.14 & 0.35 & 0.12 & 0.33 & 0.18 & 0.38 & 0.15 & 0.35 \\
\hline Separated, Divorced or Widowed & 0.10 & 0.30 & 0.12 & 0.32 & 0.06 & 0.23 & 0.07 & 0.25 \\
\hline Head is in paid work, more than 15 hours & 0.53 & 0.50 & 0.48 & 0.50 & 0.60 & 0.49 & 0.64 & 0.48 \\
\hline Head is working part-time & 0.07 & 0.25 & 0.07 & 0.25 & 0.08 & 0.27 & 0.05 & 0.21 \\
\hline Head retired & 0.15 & 0.36 & 0.19 & 0.39 & 0.09 & 0.28 & 0.06 & 0.24 \\
\hline Head unemployed & 0.17 & 0.38 & 0.15 & 0.35 & 0.23 & 0.42 & 0.23 & 0.42 \\
\hline Number of earners in household (active) & 1.61 & 1.14 & 1.58 & 1.13 & 1.63 & 1.15 & 1.61 & 1.12 \\
\hline Head university education & 0.04 & 0.20 & 0.03 & 0.16 & 0.07 & 0.25 & 0.06 & 0.24 \\
\hline Head secondary education & 0.07 & 0.25 & 0.06 & 0.24 & 0.08 & 0.28 & 0.13 & 0.34 \\
\hline \multicolumn{9}{|l|}{ Characteristics of Spells } \\
\hline Non-censored observations & 0.63 & 0.48 & 0.68 & 0.47 & 0.59 & 0.49 & 0.68 & 0.47 \\
\hline Elapsed duration (years) & 2.17 & 1.68 & 2.40 & 1.90 & 1.82 & 1.06 & 1.67 & 1.19 \\
\hline Lagged poverty duration (years) & & & - & - & 1.78 & 1.02 & & \\
\hline Lagged accum. pov. duration (years) & & & - & - & 3.60 & 1.39 & & \\
\hline Lagged non-poverty duration (years) & & & - & - & 1.73 & 1.02 & & \\
\hline Lagged accum. non pov. duration (years) & & & - & - & 1.73 & 1.02 & & \\
\hline
\end{tabular}

Note: These results omit the percentage of missings in variables for which children have no information available. 
Table 10. Discrete hazard models for all poverty exits and all poverty re-entries, by spell order controlling for unobserved heterogeneity).

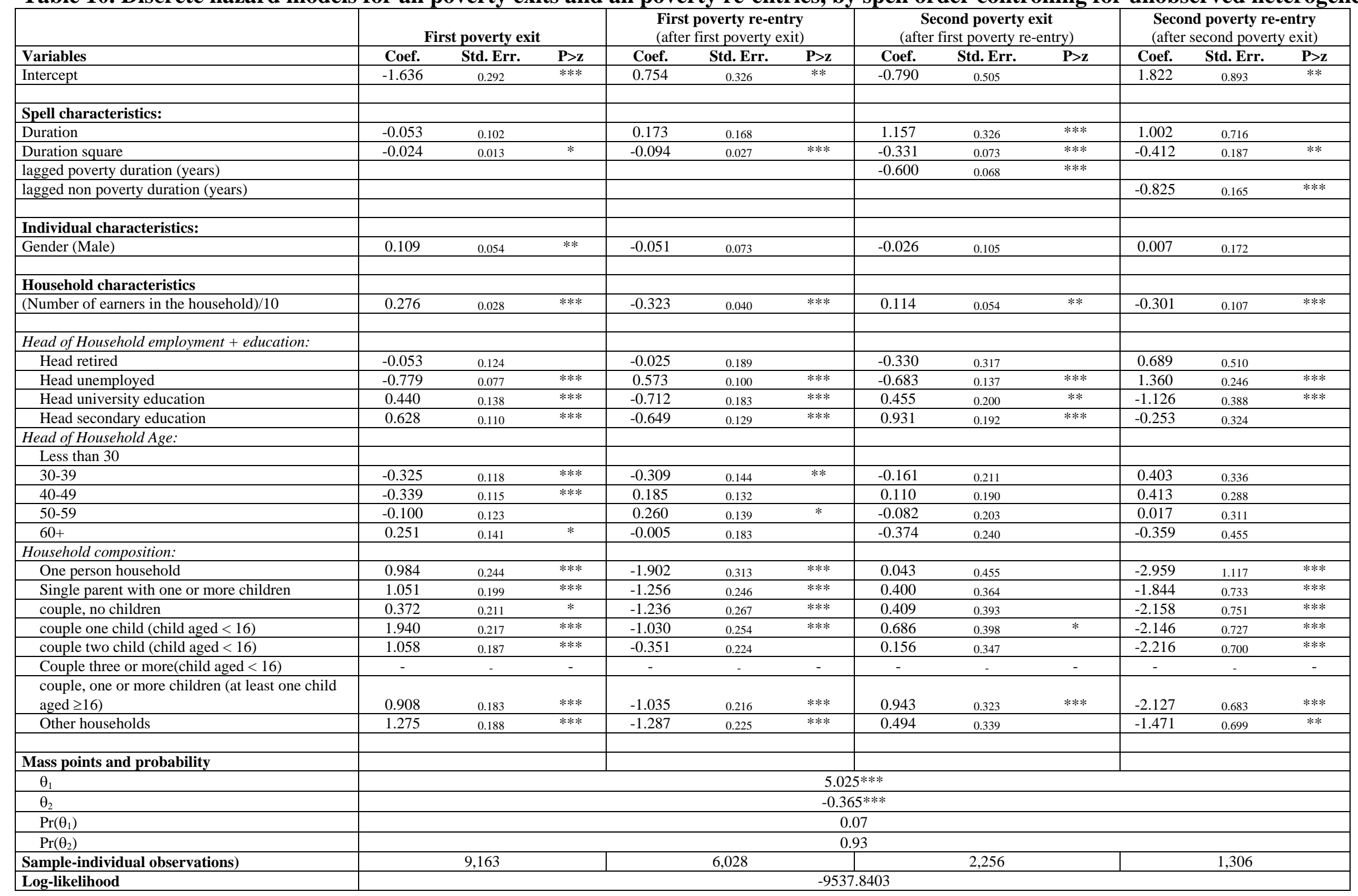

Log-likelihood

*** Indicates significance at 1 per cent; ** indicates significance at 5 per cent; * indicates significance at 1 per cent.

Note: The reference individual is a female living in a household whose head is less than 30 years of age, has less than secondary education and is employed. The household includes three or more children. 
Figure 4. Baseline hazard rate for poverty and non poverty exit after controlling observed and unobserved het.

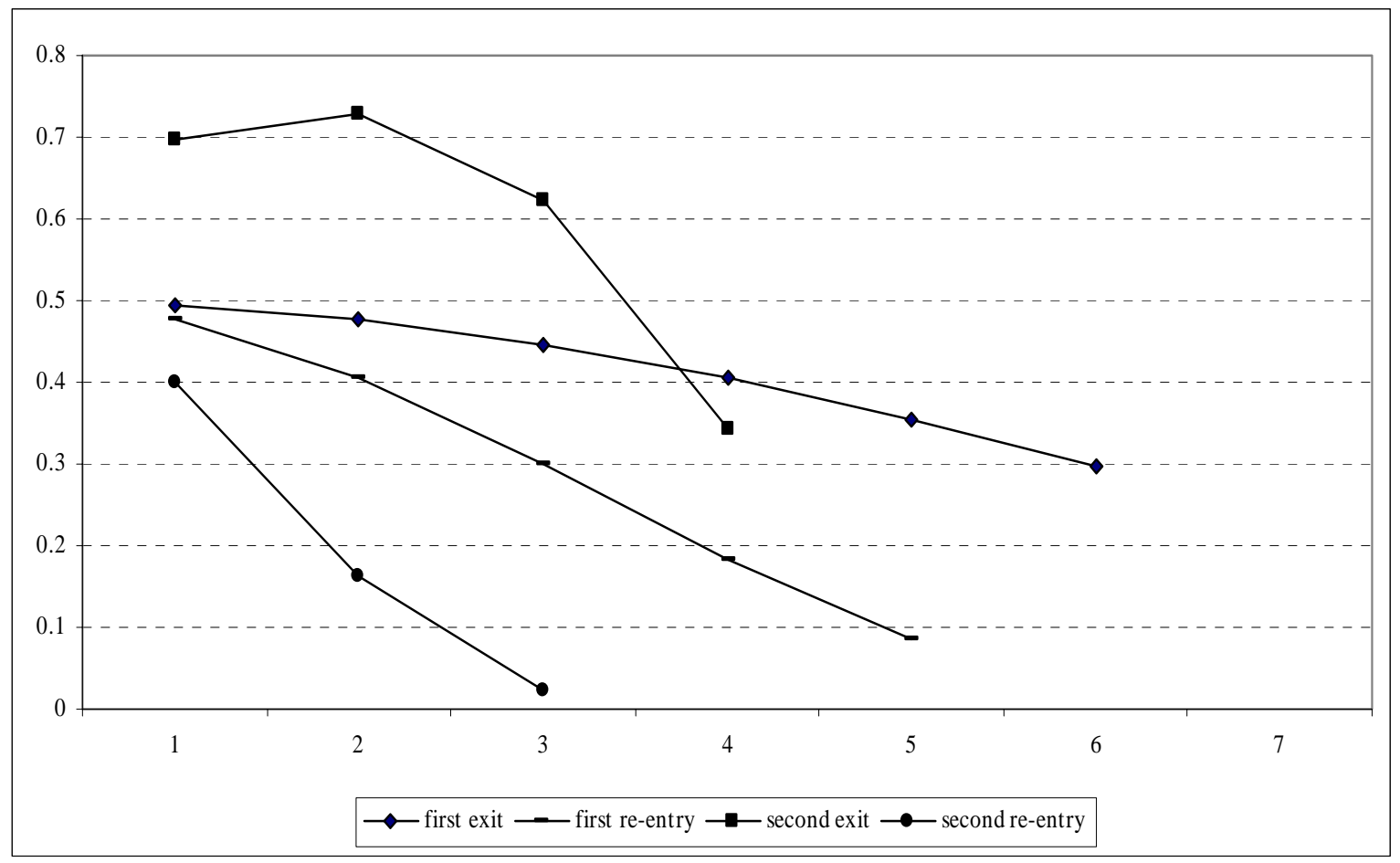


Table 11. Frequency distributions of elapsed durations, all spells.

Sample restricted to individuals who enter poverty in 1995. ECHP 1994-2000. (New entrants sample)

\begin{tabular}{ccccc}
\hline Elapsed duration & all poverty spells & \multicolumn{2}{c}{ All non-poverty spells } \\
\hline & Freq & $\mathbf{\%}$ & Freq & $\mathbf{\%}$ \\
\hline $\mathbf{1}$ & 614 & 54.1 & 263 & 29 \\
$\mathbf{2}$ & 252 & 22.2 & 210 & 23.1 \\
$\mathbf{3}$ & 133 & 11.7 & 151 & 16.6 \\
$\mathbf{4}$ & 60 & 5.3 & 98 & 10.8 \\
$\mathbf{5}$ & 24 & 2.1 & 185 & 20.4 \\
$\mathbf{6}$ & 52 & 4.6 & & \\
$\mathbf{7}$ & & & & \\
\hline Total individuals & 1,135 & 100 & 907 & \\
\hline Mean (Std. Dev.) & $1.93(1.34)$ & & $2.71(1.49)$ & \\
\hline
\end{tabular}

Table 12. Number of spells of poverty and non-poverty in new entrants sample. Sample restricted to individuals who enter poverty in 1995. ECHP 1994-2000. (New entrants sample)

\begin{tabular}{ccccc}
\hline Number of occurrences & \multicolumn{2}{c}{ Poverty } & \multicolumn{2}{c}{ Non-Poverty } \\
\hline & Freq. & $\mathbf{\%}$ & Freq. & \% \\
\hline $\mathbf{1}$ & 704 & 62.03 & 706 & 62.20 \\
$\mathbf{2}$ & 403 & 35.51 & 195 & 17.18 \\
$\mathbf{3}$ & 28 & 2.47 & 6 & 0.53 \\
\hline Total individuals & 1,135 & 100 & 907 & 79.91 \\
\hline
\end{tabular}

Nota: The percentages are calculated over the total sample of individuals $(1,135)$

Table 13. Frequency distributions of elapsed durations by order of occurrence.

Sample restricted to individuals who enter poverty in 1995. ECHP 1994-2000. (New entrants sample)

\begin{tabular}{|c|c|c|c|c|c|c|c|c|c|c|c|c|}
\hline \multirow[t]{2}{*}{$\begin{array}{l}\text { Elapsed } \\
\text { duration }\end{array}$} & \multicolumn{2}{|c|}{$\begin{array}{c}\text { First poverty } \\
\text { spell }\end{array}$} & \multicolumn{2}{|c|}{$\begin{array}{c}\text { First non-poverty } \\
\text { spell } \\
\end{array}$} & \multicolumn{2}{|c|}{$\begin{array}{c}\text { Second poverty } \\
\text { spell } \\
\end{array}$} & \multicolumn{2}{|c|}{$\begin{array}{l}\text { Second non- } \\
\text { poverty spell }\end{array}$} & \multicolumn{2}{|c|}{$\begin{array}{c}\text { Third poverty } \\
\text { spell } \\
\end{array}$} & \multicolumn{2}{|c|}{$\begin{array}{l}\text { Third non- } \\
\text { poverty spell }\end{array}$} \\
\hline & Freq & $\%$ & Freq & $\%$ & Freq & $\%$ & Freq & $\%$ & Freq & $\%$ & Freq & $\%$ \\
\hline 1 & 767 & 67.58 & 344 & 37.93 & 256 & 59.40 & 101 & 50.25 & 15 & 53.57 & 6 & 100 \\
\hline 2 & 172 & 15.15 & 168 & 18.52 & 102 & 23.67 & 61 & 30.35 & 13 & 46.43 & - & - \\
\hline 3 & 77 & 6.78 & 112 & 12.35 & 56 & 12.99 & 39 & 19.40 & - & - & - & - \\
\hline 4 & 43 & 3.79 & 98 & 10.80 & 17 & 3.94 & - & - & - & - & - & - \\
\hline 5 & 24 & 2.11 & 185 & 20.40 & - & - & - & - & - & - & - & - \\
\hline 6 & 52 & 4.58 & - & - & - & - & - & - & - & - & - & - \\
\hline 7 & - & - & - & - & - & - & - & - & - & - & - & - \\
\hline $\begin{array}{c}\text { Total } \\
\text { individuals }\end{array}$ & 1,135 & 100 & 907 & 100 & 431 & 100 & 201 & 100 & 28 & 100 & 6 & 100 \\
\hline $\begin{array}{c}\text { Mean } \\
\text { (Std. Dev.) }\end{array}$ & 1.71 & $.32)$ & & & & & & & & & & \\
\hline
\end{tabular}


Table 14. Life tables estimates of hazard rates, survival probability and cumulative failure for all poverty exits and re-entries.

Based on all poverty spells observed from ECHP waves 1994-2000 for individuals who enter poverty in 1995.

\begin{tabular}{|c|c|c|c|c|c|c|c|c|c|}
\hline \multicolumn{2}{|c|}{$\begin{array}{c}\text { Interval } \\
\text { (years) }\end{array}$} & $\begin{array}{l}\text { Total number of } \\
\text { individuals at risk } \\
\text { Total (individuals) }\end{array}$ & Deaths & Lost & Survival(\%) & $\begin{array}{l}\text { Cum. } \\
\text { Failure } \\
(\%)\end{array}$ & $\begin{array}{l}\text { Std. } \\
\text { Error }\end{array}$ & $\begin{array}{c}\text { Hazard } \\
(\%)\end{array}$ & $\begin{array}{l}\text { Std. } \\
\text { Error }\end{array}$ \\
\hline \multicolumn{10}{|c|}{ All exits } \\
\hline 1 & 2 & 1594 & 799 & 239 & 0.46 & 0.54 & 0.01 & 0.74 & 0.02 \\
\hline 2 & 3 & 556 & 174 & 113 & 0.30 & 0.70 & 0.01 & 0.42 & 0.03 \\
\hline 3 & 4 & 269 & 85 & 48 & 0.20 & 0.81 & 0.01 & 0.42 & 0.04 \\
\hline 4 & 5 & 136 & 39 & 21 & 0.13 & 0.87 & 0.01 & 0.37 & 0.06 \\
\hline 5 & 6 & 76 & 17 & 7 & 0.10 & 0.90 & 0.01 & 0.27 & 0.06 \\
\hline 6 & 7 & 52 & 0 & 52 & 0.10 & 0.90 & 0.01 & 0.00 & \\
\hline 7 & 8 & & & & & & & & \\
\hline \multicolumn{10}{|c|}{ All entries and re-entries } \\
\hline 1 & 2 & 1114 & 269 & 182 & 0.74 & 0.26 & 0.01 & 0.30 & 0.02 \\
\hline 2 & 3 & 663 & 99 & 130 & 0.62 & 0.39 & 0.02 & 0.18 & 0.02 \\
\hline 3 & 4 & 434 & 57 & 94 & 0.52 & 0.48 & 0.02 & 0.16 & 0.02 \\
\hline 4 & 5 & 283 & 34 & 64 & 0.45 & 0.55 & 0.02 & 0.15 & 0.02 \\
\hline 5 & 6 & 185 & 0 & 185 & 0.45 & 0.55 & 0.02 & 0.00 & \\
\hline 6 & 7 & & & & & & & & \\
\hline
\end{tabular}


Table 15. Life tables estimates of hazard rates, survival probability and cumulative failure by order of occurrence.

Based on all poverty spells observed from ECHP waves 1994-2000 for individuals who enter poverty in 1995.

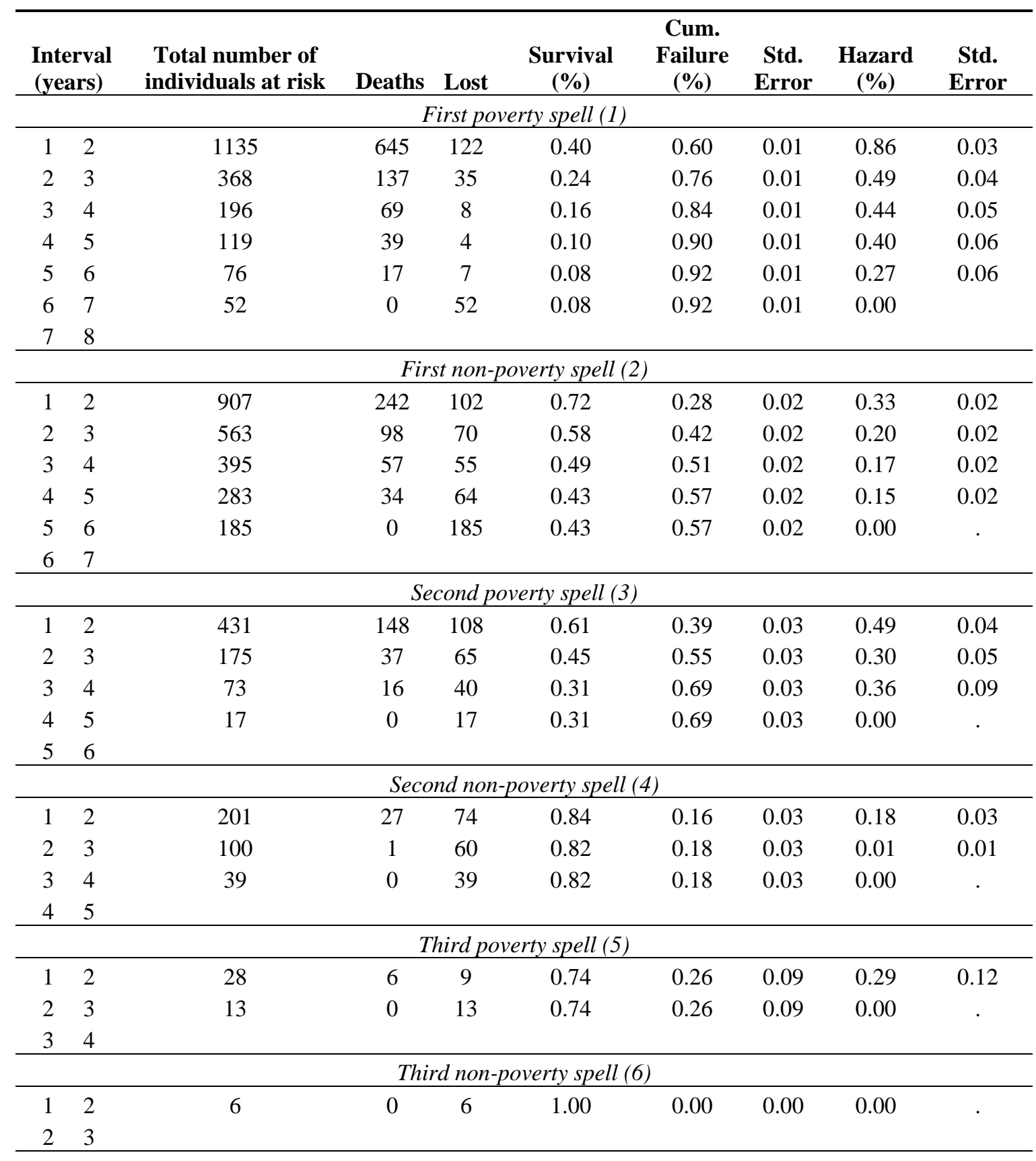

Fourth poverty spell (7) 
Table 16. Hazard models for all poverty exits and all poverty re-entries, by spell order controlling unobserved heterogeneity). New entrants in 1995.

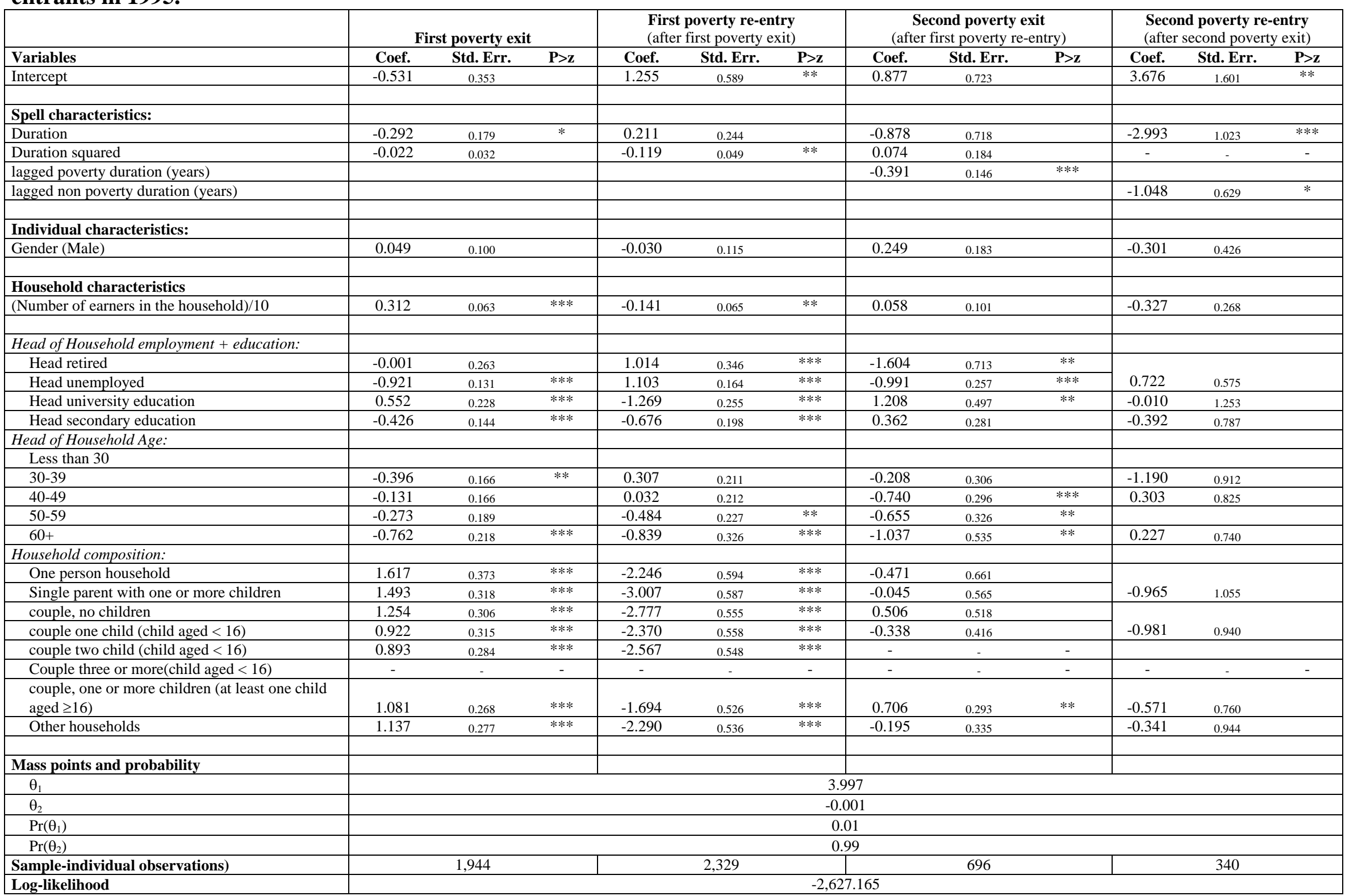

*** Indicates significance at 1 per cent; ** indicates significance at 5 per cent; * indicates significance at 1 per cent.

Note: The reference individual is a female living in a household whose head is less than 30 years of age, has less than secondary education and is employed. The household includes three or more children. 


\section{APPENDIX}

Table A1. Final Panel Sample for Spain, ECHP (1994-2001), using contemporaneous current household income data

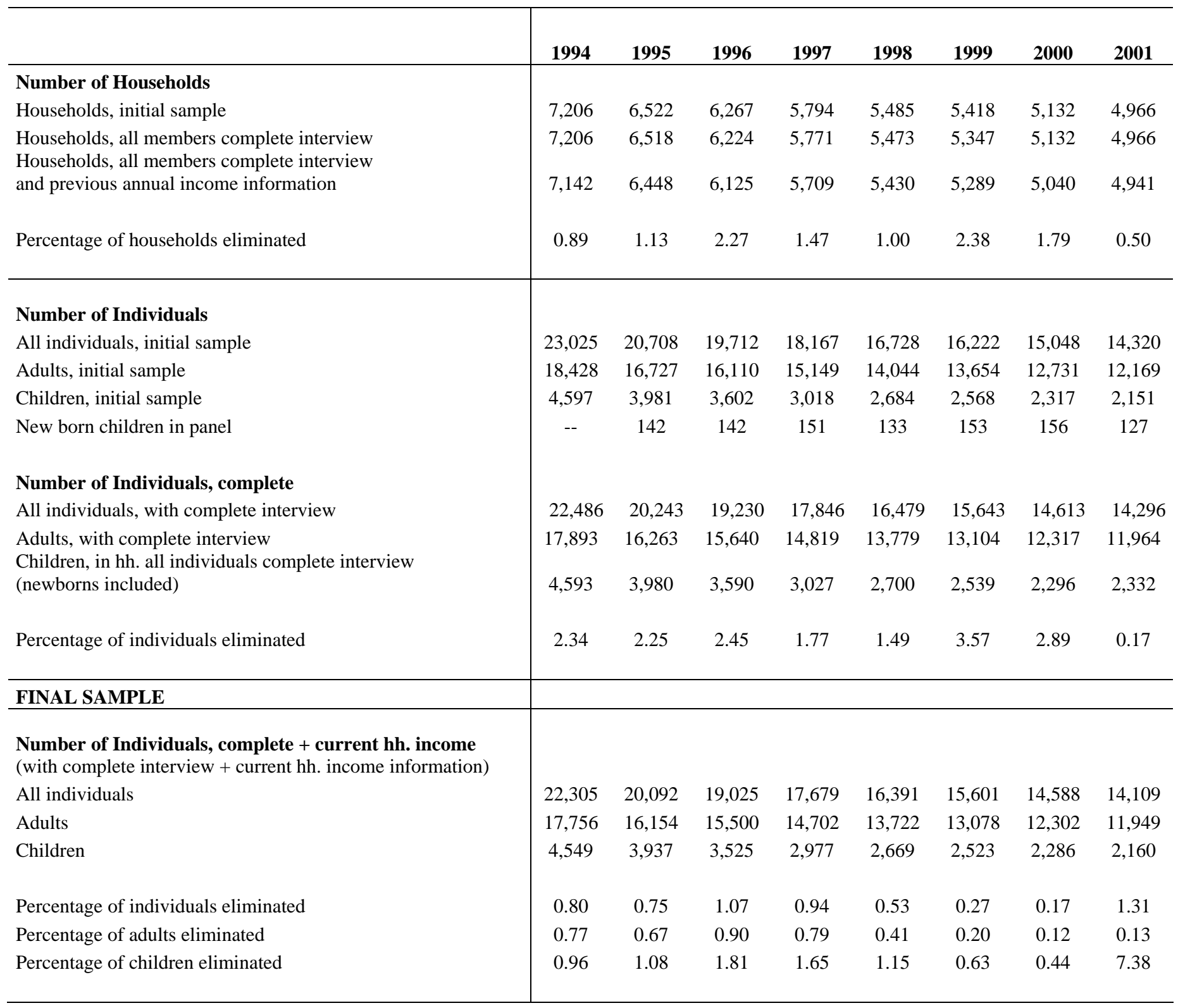

Source: Own construction using ECHP (1994-2001). 
Table A2. Final Panel Sample for Spain, ECHP (1994-2000), using contemporaneous information for household income and household characteristics

\begin{tabular}{|c|c|c|c|c|c|c|c|}
\hline & \multicolumn{7}{|c|}{ Different year of observation of household income \& household characteristics } \\
\hline & 1993/1994 & 1994/1995 & 1995/1996 & 1996/1997 & 1997/1998 & 1998/1999 & 1999/2000 \\
\hline \multicolumn{8}{|c|}{$\begin{array}{l}\text { of Individuals, complete }+ \text { hh. income } \\
\text { omplete interview }+ \text { hh. income information) }\end{array}$} \\
\hline \multirow{5}{*}{ ividuals } & 22,305 & 20,092 & 19,025 & 17,679 & 16,391 & 15,601 & 14,588 \\
\hline & 17,756 & 16,154 & 15,500 & 14,702 & 13,722 & 13,078 & 12,302 \\
\hline & 4,549 & 3,937 & 3,525 & 2,977 & 2,669 & 2,523 & 2,286 \\
\hline & \multicolumn{7}{|c|}{ Contemporary year of observation of household income \& household characteristics } \\
\hline & 1994 & 1995 & 1996 & 1997 & 1998 & 1999 & 2000 \\
\hline \\
\hline \multirow[t]{3}{*}{ ividuals } & 19,044 & 17,754 & 16,496 & 15,402 & 14,519 & 13,740 & 13,251 \\
\hline & 15,042 & 14,216 & 13,374 & 12,800 & 12,088 & 11,489 & 11,147 \\
\hline & 4,002 & 3,538 & 3,122 & 2,602 & 2,431 & 2,251 & 2,104 \\
\hline age of individuals eliminated & 14.62 & 11.64 & 13.29 & 12.88 & 11.42 & 11.93 & 9.17 \\
\hline age of adults eliminated & 15.28 & 12.00 & 13.72 & 12.94 & 11.91 & 12.15 & 9.39 \\
\hline age of children eliminated & 12.02 & 10.13 & 11.43 & 12.60 & 8.92 & 10.78 & 7.96 \\
\hline
\end{tabular}

Source: Own construction using ECHP (1994-2001). 
Table A3. Poverty Incidence and Short-term Persistence.

Sample including individuals that join the panel (with and without selection, weighted) ECHP 1994-2000.

\begin{tabular}{|c|c|c|c|c|c|c|c|}
\hline & 1994 & 1995 & 1996 & 1997 & 1998 & 1999 & 2000 \\
\hline \multicolumn{8}{|l|}{ Incidence } \\
\hline \multicolumn{8}{|l|}{ Headcount index (\% poor) } \\
\hline $\begin{array}{l}\text { Headcount index (\% poor) } \\
\text { (over sample size without }\end{array}$ & 19.88 & 19.67 & 18.46 & 21.32 & 19.43 & 20.16 & 18.99 \\
\hline \multicolumn{8}{|l|}{ Conditional probabilities } \\
\hline \multicolumn{8}{|l|}{ Poverty persistence } \\
\hline $\operatorname{Prob}\left(\mathrm{y}_{\mathrm{t}}=1 / \mathrm{y}_{\mathrm{t}-1}=1\right)$ & & 52.31 & 48.3 & 53.17 & 51.27 & 53.23 & 53.45 \\
\hline \multicolumn{8}{|l|}{ Poverty entry occurs } \\
\hline $\operatorname{Prob}\left(\mathrm{y}_{\mathrm{t}}=1 / \mathrm{y}_{\mathrm{t}-1}=0\right)$ & & 7.87 & 7.82 & 10.6 & 7.22 & 8.74 & 8.34 \\
\hline \multicolumn{8}{|l|}{ Poverty exit occurs } \\
\hline $\operatorname{Prob}\left(\mathrm{y}_{\mathrm{t}}=0 / \mathrm{y}_{\mathrm{t}-1}=1\right)$ & & 35.17 & 39.85 & 33.76 & 38.35 & 36.69 & 39.3 \\
\hline \multicolumn{8}{|l|}{ Persistence out of poverty } \\
\hline $\operatorname{Prob}\left(\mathrm{y}_{\mathrm{t}}=0 / \mathrm{y}_{\mathrm{t}-1}=0\right)$ & & 81.58 & 80.2 & 78.85 & 82.28 & 79.72 & 84.27 \\
\hline \multicolumn{8}{|l|}{ Atrittion occurs } \\
\hline Prob $\left(\mathrm{y}_{\mathrm{t}}=\mathrm{mis} / \mathrm{y}_{\mathrm{t}-1}=0\right)$ & & 10.54 & 11.99 & 10.55 & 10.5 & 11.54 & 7.39 \\
\hline Prob $\left(\mathrm{y}_{\mathrm{t}}=\mathrm{mis} / \mathrm{y}_{\mathrm{t}-1}=1\right)$ & & 12.51 & 11.85 & 13.07 & 10.38 & 10.08 & 7.25 \\
\hline \multicolumn{8}{|l|}{ Individuals join panel } \\
\hline $\operatorname{Prob}\left(\mathrm{y}_{\mathrm{t}}=1 / \mathrm{y}_{\mathrm{t}-1}=m i s\right)$ & & 8.74 & 5.8 & 5.28 & 3.39 & 3.1 & 1.94 \\
\hline $\operatorname{Prob}\left(\mathrm{y}_{\mathrm{t}}=0 / \mathrm{y}_{\mathrm{t}-1}=m i s\right)$ & & 19.79 & 16.59 & 9.15 & 6.39 & 5.91 & 4.64 \\
\hline $\operatorname{Prob}\left(\mathrm{y}_{\mathrm{t}}=m i s / \mathrm{y}_{\mathrm{t}-1}=m i s\right)$ & & 71.47 & 77.61 & 85.56 & 90.22 & 90.99 & 93.42 \\
\hline Sample size & 22,539 & 22,539 & 22,539 & 22,539 & 22,539 & 22,539 & 22,539 \\
\hline $\begin{array}{c}\text { Sample size, } \\
\text { no missing values(4) }\end{array}$ & 19,044 & 17,754 & 16,496 & 15,402 & 14,519 & 13,740 & 13,251 \\
\hline
\end{tabular}

Notes: $\mathrm{y}_{\mathrm{t}}=1$ if the individual is in poverty at time $\mathrm{t}$ and $\mathrm{y}_{\mathrm{t}}=0$ if the individual is out of poverty at time $\mathrm{t}, \mathrm{y}_{\mathrm{t}}=$ mis if individual information is missing (attrition occurred or individual not present in the ECHP panel that year). 
Table A4. Incidence of Poverty, Poverty Persistence and Transitions. Inflow to poverty sample (with and without selection, weighted)

ECHP 1994-2000.

\begin{tabular}{|c|c|c|c|c|c|c|c|}
\hline & 1994 & 1995 & 1996 & 1997 & 1998 & 1999 & 2000 \\
\hline \multicolumn{8}{|l|}{ Incidence } \\
\hline \multirow{2}{*}{$\begin{array}{l}\text { Headcount index (\% poor) } \\
\text { (over sample size) } \\
\text { Headcount index (\% poor) } \\
\text { (over sample size without } \\
\text { missing values) }\end{array}$} & & 100 & 31.08 & 33.23 & 24.50 & 25.70 & 24.35 \\
\hline & & 100 & 35.94 & 44.12 & 34.80 & 36.96 & 36.63 \\
\hline \multicolumn{8}{|l|}{ Conditional probabilities } \\
\hline \multicolumn{8}{|l|}{ Poverty persistence } \\
\hline $\operatorname{Prob}\left(\mathrm{y}_{\mathrm{t}}=1 / \mathrm{y}_{\mathrm{t}-1}=1\right)$ & & & 31.08 & 49.87 & 49.08 & 55.15 & 66.36 \\
\hline \multicolumn{8}{|l|}{ Poverty entry occurs } \\
\hline $\operatorname{Prob}\left(\mathrm{y}_{\mathrm{t}}=1 / \mathrm{y}_{\mathrm{t}-1}=0\right)$ & & & & 32.03 & 16.39 & 21.27 & 14.47 \\
\hline \multicolumn{8}{|l|}{ Poverty exit occurs } \\
\hline $\operatorname{Prob}\left(\mathrm{y}_{\mathrm{t}}=0 / \mathrm{y}_{\mathrm{t}-1}=1\right)$ & & & 55.4 & 34.81 & 39.72 & 36.79 & 26.72 \\
\hline \multicolumn{8}{|l|}{ Persistence out of poverty } \\
\hline $\operatorname{Prob}\left(\mathrm{y}_{\mathrm{t}}=0 / \mathrm{y}_{\mathrm{t}-1}=0\right)$ & & & & 56.17 & 74.27 & 71.84 & 76.86 \\
\hline \multicolumn{8}{|l|}{ Atrittion occurs } \\
\hline $\operatorname{Prob}\left(\mathrm{y}_{\mathrm{t}}=\mathrm{mis} / \mathrm{y}_{\mathrm{t}-1}=0\right)$ & & & & 11.81 & 9.33 & 6.89 & 8.67 \\
\hline $\operatorname{Prob}\left(\mathrm{y}_{\mathrm{t}}=\mathrm{mis} / \mathrm{y}_{\mathrm{t}-1}=1\right)$ & & & 13.52 & 15.32 & 11.2 & 8.07 & 6.92 \\
\hline Sample size & & 1,244 & 1,244 & 1,244 & 1,244 & 1,244 & 1,244 \\
\hline $\begin{array}{c}\text { Sample size, } \\
\text { no missing values(4) }\end{array}$ & & 1,244 & 1,076 & 937 & 876 & 865 & 827 \\
\hline
\end{tabular}

Notes: $\mathrm{y}_{\mathrm{t}}=1$ if the individual is in poverty at time $\mathrm{t}$ and $\mathrm{y}_{\mathrm{t}}=0$ if the individual is out of poverty at time $\mathrm{t}$, $\mathrm{y}_{\mathrm{t}}=$ mis if individual information is missing (attrition occurred or individual not present in the ECHP panel that year). 
Table A5. Characteristics of the samples of poverty spells, individuals: Means and standard errors.

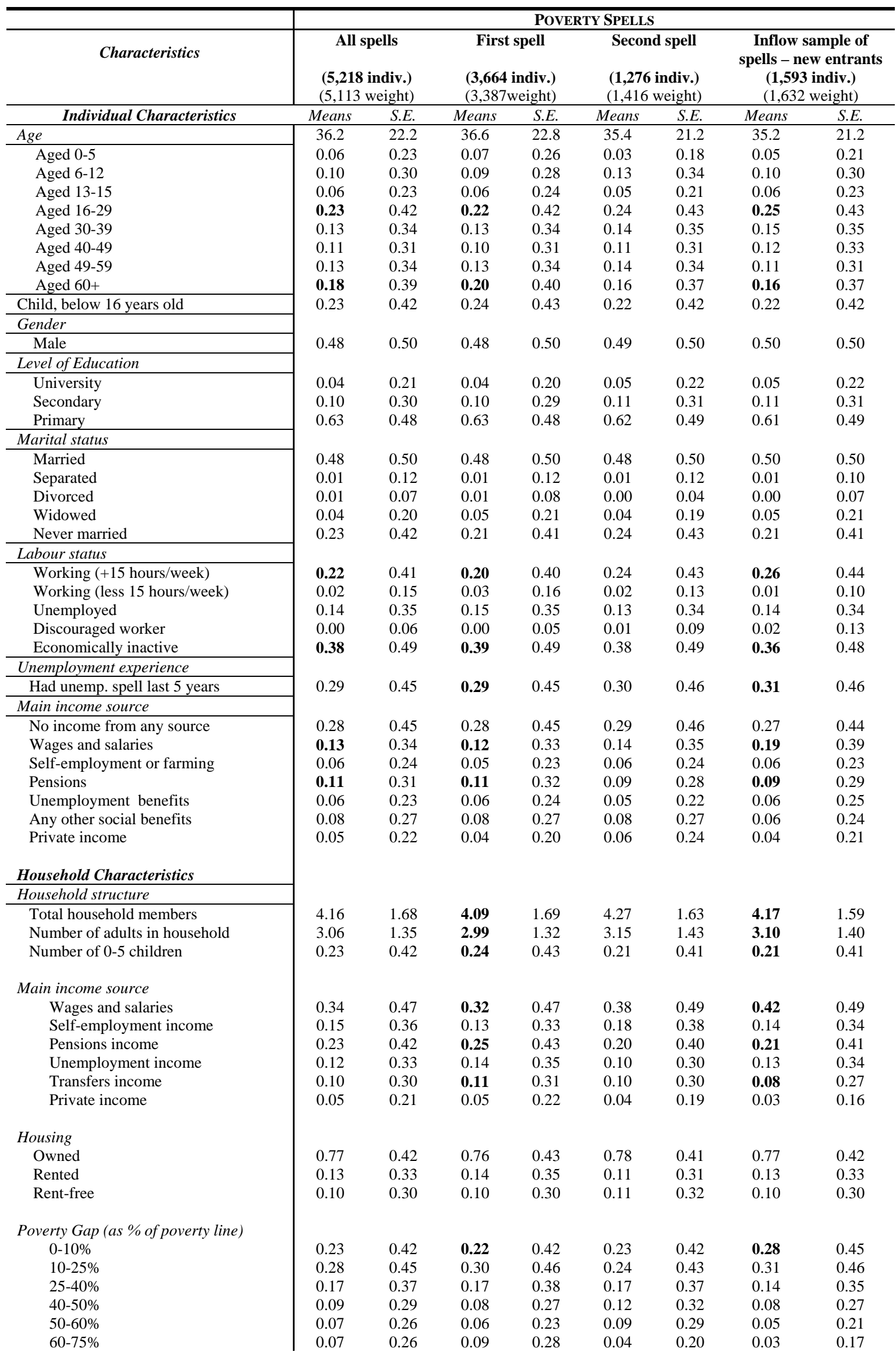




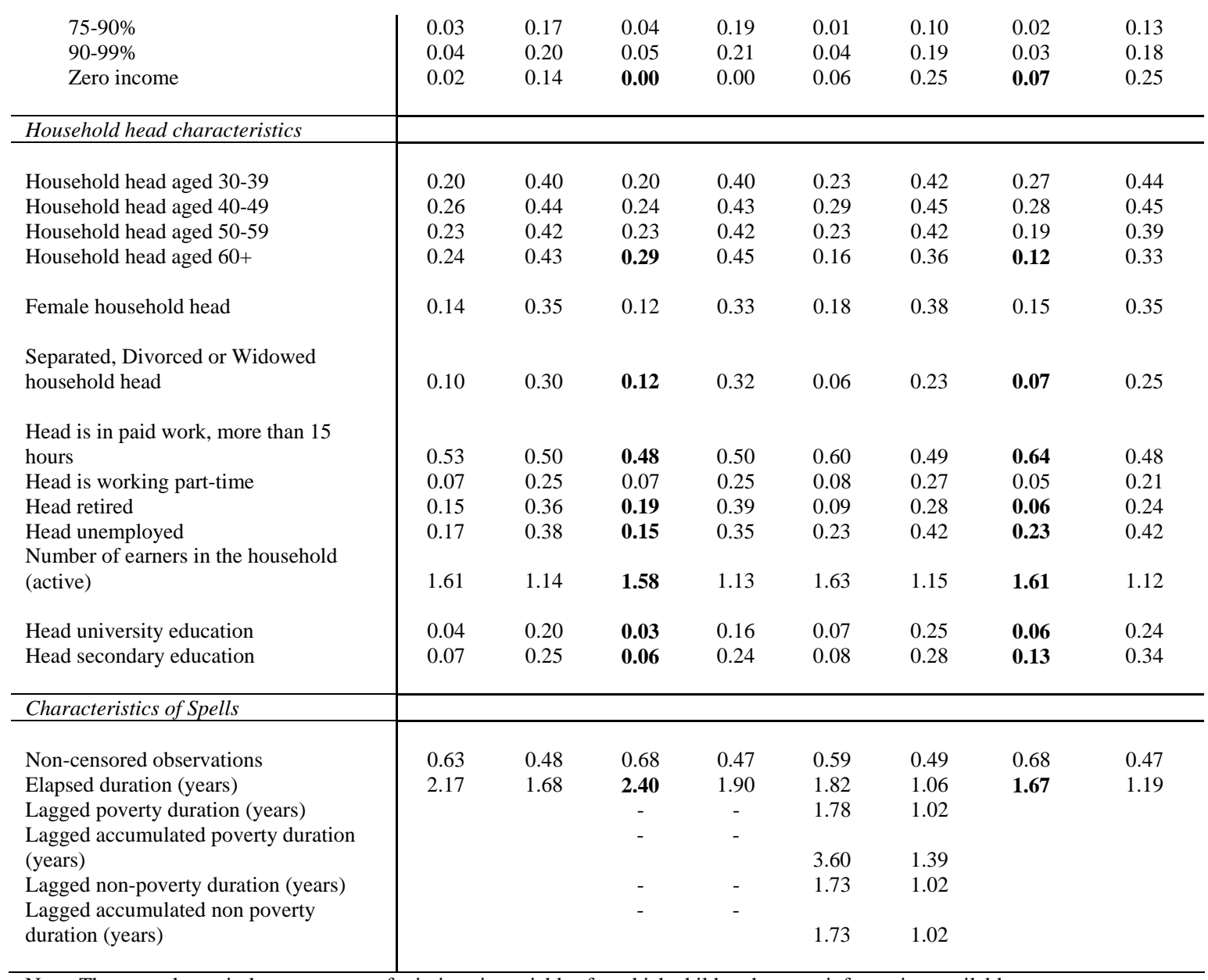

Note: These results omit the percentage of missings in variables for which children have no information available.

Source: Own construction using the ECHP 1994-2000. 
Table A6. Poverty Incidence and Short-term Persistence.

Individuals age $<\mathbf{1 6}$.

ECHP 1994-2000.

\begin{tabular}{lccccccc} 
& 1994 & 1995 & 1996 & 1997 & 1998 & 1999 & 2000 \\
\hline $\begin{array}{l}\text { Incidence } \\
\text { Headcount index (\% poor) }\end{array}$ & 23.83 & 23.89 & 24.27 & 25.4 & 25.7 & 25.87 & 27.55
\end{tabular}

\section{Conditional probabilities}

Poverty short-term persistence

Prob $\left(\mathrm{y}_{\mathrm{t}}=1 / \mathrm{y}_{\mathrm{t}-1}=1\right)$

$\begin{array}{llllll}57.78 & 56.72 & 56.23 & 59.83 & 57.96 & 61.58\end{array}$

Poverty entry occurs

Prob $\left(\mathrm{y}_{\mathrm{t}}=1 / \mathrm{y}_{\mathrm{t}-1}=0\right)$

$\begin{array}{llllll}10.31 & 10.31 & 12.37 & 9.86 & 12.02 & 11.41\end{array}$

Poverty exit occurs

Prob $\left(\mathrm{y}_{\mathrm{t}}=0 / \mathrm{y}_{\mathrm{t}-1}=1\right)$

$\begin{array}{cccccc}30.97 & 33.06 & 28.77 & 33.02 & 33.92 & 33.62 \\ 81.2 & 79.67 & 77.6 & 81.69 & 78.84 & 82.19 \\ & & & & & \\ 8.49 & 10.03 & 10.03 & 8.45 & 9.14 & 6.4 \\ 11.25 & 10.23 & 15 & 7.15 & 8.13 & 4.8\end{array}$

Persistence out of poverty

$\operatorname{Prob}\left(\mathrm{y}_{\mathrm{t}}=0 / \mathrm{y}_{\mathrm{t}-1}=0\right)$

Atrittion

Prob $\left(\mathrm{y}_{\mathrm{t}}=\mathrm{mis} / \mathrm{y}_{\mathrm{t}-1}=0\right)$

$\begin{array}{lll}11.25 & 10.23 \quad 15\end{array}$

7.15

8.13

4.8

Note: These results are obtained using the ECHP contemporary income and characteristics information and using a modified OECD equivalence scale. Calculations of headcound index are made for individuals weighted by their population weight each particular year. The sample here is that of all individuals present in 1994 and in consecutive interviews in the ECHP panel until the survey ends or they suffer from attrition. Note that $\mathrm{y}_{\mathrm{t}}=1$ if the individual is poor in time $\mathrm{t}$ and 0 if the individual is non-poor, "mis"means that attrition occurred.

Table A7. Poverty Incidence and Short-term Persistence.

Individuals age $>=16$ and $<=65$.

ECHP 1994-2000.

\begin{tabular}{|c|c|c|c|c|c|c|c|}
\hline & 1994 & 1995 & 1996 & 1997 & 1998 & 1999 & 2000 \\
\hline \multicolumn{8}{|l|}{ Incidence } \\
\hline Headcount index (\% poor) & 19.4 & 18.74 & 17.41 & 21.24 & 18.38 & 18.75 & 17.31 \\
\hline \multicolumn{8}{|c|}{ Conditional probabilities } \\
\hline \multicolumn{8}{|c|}{ Poverty short-term persistence } \\
\hline $\operatorname{Prob}\left(\mathrm{y}_{\mathrm{t}}=1 / \mathrm{y}_{\mathrm{t}-1}=1\right)$ & & 50.81 & 45.85 & 52.66 & 47.79 & 51.19 & 50.65 \\
\hline \multicolumn{8}{|l|}{ Poverty entry occurs } \\
\hline $\operatorname{Prob}\left(\mathrm{y}_{\mathrm{t}}=1 / \mathrm{y}_{\mathrm{t}-1}=0\right)$ & & 7.74 & 7.86 & 10.97 & 7.01 & 8.02 & 7.71 \\
\hline \multicolumn{8}{|l|}{ Poverty exit occurs } \\
\hline $\operatorname{Prob}\left(\mathrm{y}_{\mathrm{t}}=0 / \mathrm{y}_{\mathrm{t}-1}=1\right)$ & & 37.37 & 42.61 & 35.49 & 41.85 & 38.83 & 43.21 \\
\hline \multicolumn{8}{|l|}{ Persistence out of poverty } \\
\hline $\operatorname{Prob}\left(\mathrm{y}_{\mathrm{t}}=0 / \mathrm{y}_{\mathrm{t}-1}=0\right)$ & & 81.91 & 80.35 & 78.71 & 83.27 & 81.09 & 85.53 \\
\hline \multicolumn{8}{|l|}{ Atrittion } \\
\hline $\operatorname{Prob}\left(\mathrm{y}_{\mathrm{t}}=\mathrm{mis} / \mathrm{y}_{\mathrm{t}-1}=0\right)$ & & 10.35 & 11.79 & 10.32 & 9.72 & 10.89 & 6.76 \\
\hline $\operatorname{Prob}\left(\mathrm{y}_{\mathrm{t}}=\mathrm{mis} / \mathrm{y}_{\mathrm{t}-1}=1\right)$ & & 11.82 & 11.55 & 11.85 & 10.36 & 9.98 & 6.15 \\
\hline
\end{tabular}

Note: See note in Table A.7.

Table A8. Poverty Incidence and Short-term Persistence. 
Individuals age $>\mathbf{6 5}$.

ECHP 1994-2000.

\begin{tabular}{|c|c|c|c|c|c|c|c|}
\hline & 1994 & 1995 & 1996 & 1997 & 1998 & 1999 & 2000 \\
\hline \multicolumn{8}{|l|}{ Incidence } \\
\hline Headcount index (\% poor) & 17.07 & 14.83 & 12.86 & 15.30 & 14.38 & 17.61 & 17.88 \\
\hline \multicolumn{8}{|c|}{ Conditional probabilities } \\
\hline \multicolumn{8}{|c|}{ Poverty short-term persistence } \\
\hline $\operatorname{Prob}\left(\mathrm{y}_{\mathrm{t}}=1 / \mathrm{y}_{\mathrm{t}-1}=1\right)$ & & 49.21 & 52.72 & 61.87 & 58.13 & 64.2 & 60.42 \\
\hline \multicolumn{8}{|l|}{ Poverty entry occurs } \\
\hline $\operatorname{Prob}\left(\mathrm{y}_{\mathrm{t}}=1 / \mathrm{y}_{\mathrm{t}-1}=0\right)$ & & 5.27 & 3.62 & 6.42 & 4.27 & 8.25 & 8.24 \\
\hline \multicolumn{7}{|l|}{ Poverty exit occurs } & 26.04 \\
\hline \multicolumn{8}{|l|}{ Persistence out of poverty } \\
\hline $\operatorname{Prob}\left(\mathrm{y}_{\mathrm{t}}=0 / \mathrm{y}_{\mathrm{t}-1}=0\right)$ & & 80.53 & 82.09 & 83.23 & 83.46 & 79.76 & 82.26 \\
\hline \multicolumn{8}{|l|}{ Atrittion } \\
\hline $\operatorname{Prob}\left(\mathrm{y}_{\mathrm{t}}=\mathrm{mis} / \mathrm{y}_{\mathrm{t}-1}=0\right)$ & & 14.21 & 14.29 & 10.36 & 12.27 & 12 & 9.5 \\
\hline $\operatorname{Prob}\left(\mathrm{y}_{\mathrm{t}}=\mathrm{mis} / \mathrm{y}_{\mathrm{t}-1}=1\right)$ & & 19.34 & 13.55 & 10.16 & 15 & 9.95 & 13.54 \\
\hline
\end{tabular}

Note: See note in Table A7. 